NBER WORKING PAPER SERIES

\title{
DAILY MOMENTUM AND CONTRARIAN BEHAVIOR OF INDEX FUND INVESTORS
}

\author{
William N. Goetzmann \\ Massimo Massa \\ Working Paper 7567 \\ http://www.nber.org/papers/w7567 \\ NATIONAL BUREAU OF ECONOMIC RESEARCH \\ 1050 Massachusetts Avenue \\ Cambridge, MA 02138 \\ February 2000
}

We thank Fidelity for providing us with the data for this study. We thank the International Center for Finance at the Yale School of Management for providing research support. The views expressed herein are those of the authors and are not necessarily those of the National Bureau of Economic Research.

(C) 2000 by William N. Goetzmann and Massimo Massa. All rights reserved. Short sections of text, not to exceed two paragraphs, may be quoted without explicit permission provided that full credit, including (C) notice, is given to the source. 
Daily Momentum and Contrarian Behavior

of Index Fund Investors

William N. Goetzmann and Massimo Massa

NBER Working Paper No. 7567

February 2000

\begin{abstract}
We use a two-year panel of individual accounts in an S\&P 500 index mutual fund to examine the trading and investment behavior of more than 91 thousand investors who have chosen a low-cost, passively managed vehicle for savings. This allows us to characterize investors' heterogeneity in terms of their investment patterns. In particular, we identify positive feedback traders as well as contrarians whose activities are conditional upon preceding day stock market moves. We test the consistency and

profitability of these conditional strategies over time. We find that more frequent traders are typically contrarians, while infrequent traders are more typically momentum investors. The dynamics of these investor classes help us to partially examine the question of the marginal investor over the period of our study. We find that the behavior of momentum investors is typically more correlated to changes in the S\&P 500 and we trace its dynamics over time. We build up "behavioral factors" based on contrarian and momentum flows and show that they perform well against a benchmark of loadings on latent factors extracted from returns. We also use the behavior of momentum and contrarian investors to build a measure of "market polarization". This captures the dispersion of beliefs among the investors and helps to account for asset pricing better than standard measures of dispersion of beliefs.
\end{abstract}

William N. Goetzmann

Yale School of Management

Box 208200

New Haven, CT 06520-8200

and NBER

william.goetzmann@yale.edu
Massimo Massa

INSEAD

Boulevard de Constance

77305 Fontainebleau

Cedex France

massimo.massa@insead.fr 


\section{Introduction}

A number of recent models show that both momentum and contrarian investor behavior may arise and be sustained in a financial market. Barberis, Shleifer and Vishny (1998), Daniel, Hirshleifer and Subrahmanyam (1998) and Hong and Stein (1999) each develop models of investor behavior that show how common psychological heuristics, if used by market participants, may lead to both meanreverting and persistent patterns in asset prices.

Psychological heuristics are in fact not necessary to motivate momentum and contrarian behavior. Bikhchandani, Hirshleifer and Welch (1992) have a model of asymmetric information that induces market participants to ignore private information and herd. Hirshleifer, Subrahmanyam and Titman (1994) argue that information asymmetry in a market may lead to both momentum and contrarian investing. Froot, Scharfstein and Stein (1992) show how differential investor horizons and information asymmetries may correlate investor behavior and induce agents to trade on trends. Grossman (1995) shows that incomplete markets may induce dynamic portfolio choice that is conditional upon past price changes. DeLong, Shleifer, Summers and Waldman (1990) find that positive feedback trading may arise in a market and exacerbate economic shocks despite the presence of rational, informed investors. Balduzzi, Bertola and Foresi (1996) contrast destabilizing feedback traders with contrarians who effectively reduce market volatility. More recently, Orosel (1998) develops a theory of rational trend-chasing that implies time-varying market participation and volatility. In all of these models, momentum investors not only exist, but in most, they play a key role in the priceformation process.

Conditioning trades on past price dynamics makes sense in these models and empirical evidence suggests that both momentum and contrarian investing may also be profitable, depending upon the horizon of the strategy. Levy (1967), Jegadeesh and Titman (1993), Chan, Jegadeesh and Lakonishok (1996) and Rouwenhorst (1997) document profits to trading on past winning stocks both in the U.S. and abroad. Rosenberg, Reid and Lanstein (1984), DeBondt and Thaler (1985) and Lakonishok, Shleifer and Vishny (1994) show that cross-sectional contrarian investment is profitable. Lo and MacKinlay (1990) suggest that not all of this is due to behavioral heuristics. 
While many of the theoretical models cited above have been motivated in part by the compelling empirical evidence of temporal regularities in asset price patterns, direct evidence on investor behavior has been illusive.

Studies by Grinblatt, Titman and Wermers (1995) and Lakonishok, Shleifer, Thaler and Vishny (1991) focus on the behavior of institutional managers, as opposed to individuals. Gompers and Metrick (1998) study the equity holdings of large institutions for its implications for liquidity and shareholder activism. Keim and Madhavan (1995) analyze the motives for trade using a large sample of transactions by institutional managers. They find both momentum and contrarian managers in their sample, as well as a curious asymmetry in conditional purchase vs. sale decisions.

Information about individual investor behavior has been more difficult to obtain. Schlarbaum, Lewellen and Lease (1978), Lakonishok and Maberly (1990) and more recently Odean (1998) and Grinblatt and Kellaharin (1999) use individual investor account data that allows analysis about how investors (or investment groups) trade in individual securities. Odean (1998) and Grinblatt and Kellaharin (1999), for example, both document a tendency towards "loss aversion." Both also find evidence that trade decisions about individual securities in general may depend upon past individual security price paths.

In this paper we use a panel of more than 91,000 investor accounts in an S\&P 500 Index fund over a two year horizon to document daily momentum and contrarian investment with respect to a broad equity index as a whole. This is of particular interest because of the question of whether speculative trading has potential to destabilize the market. Our work differs from previous research on individual investor accounts to date in that our dataset allows us to focus entirely on investor beliefs about the stock market as a whole, rather than the relative investment prospects for individual securities.

Within the dataset, we identify sub-groups of index fund investors according to their reaction to past daily price changes. We focus on short-term momentum and contrarian behavior for two reasons. First, the limited length of our sample period limits longer-horizon analysis despite research that suggests reversion in the market over multiple-year horizons. Second, newspapers have historically attributed market drops on days following rises to "profit-taking." By examining behavior conditional upon daily market moves, our hope is to document evidence of profit-taking if such evidence exists. We find evidence for both daily momentum and daily contrarian behavior in our sample. In addition, these 
investor classes exhibit consistency through time. An investor identified as a trend-chaser or profit-taker in the first half of our sample is likely to be identified as such in the second half as well.

We find that momentum and contrarian investors differ in some key dimensions. Relatively active traders are more likely to be contrarians while infrequent traders are more likely exhibit momentum. We also find that more active investors Granger-cause less active investors -- a result that lends support to some asymmetric herding models. We find some evidence that the typical daily contrarian investor is more profitable than the typical daily momentum investor in the sample.

A key question posed by DeLong, Shleifer, Summers and Waldman (1990) is the extent to which rational momentum trading may destabilize the market. Empirical evidence suggests that mechanisms for such destabilization exists at the daily horizon. Froot, O'Connell and Seasholes (1998), Stulz (1998), Edelen and Warner (1999) and our own study, Goetzmann and Massa (1998) find that short-term fluctuations in aggregate investor demand for stocks is correlated to contemporaneous price changes and thus may move security prices. Grinblatt and Kelloharin (1999) report that the actions of foreign investors alone significantly correlate to price changes in the most active stocks in Finland. In the Finnish data, their evidence is consistent with foreign investors being the salient group, although they cannot reject the hypothesis that the correlation is solely due to same-day momentum.

We use our panel data to investigate the possible salience of different investor classes over the two-year period of our study. We use a procedure to identify which sub-groups of our data are correlates of the price-formation process through time. While we are obviously restricted to index fund investors, we find that daily momentum investors typically dominate, although at certain times in our sample, the trades of contrarians are the more salient.

Also, we use our dataset to construct "behavioral factors" based on investors' flows and to see if they span asset returns. In particular, we show that, not only do they always perform at least as well as the factors based on stock market returns, but also that it is possible to build behavioral factors based on the flows of a sub-set of investors which significantly outperform the factors based on market returns. In particular, we identify such investors in the ones who act as contrarians with respect to market volatility. This group can be thought of as "active" mean-variance optimizers who increase holdings in the risky asset when variance is low and decrease holdings when variance is high. 
Finally, we use our dataset to shed some light on the role played in asset pricing by the dispersion of beliefs. The theoretical literature has always considered the dispersion of beliefs among the investors as one of the main determinants of both asset prices and of trading volume. Williams (1977) shows how, by incorporating the effects of the heterogeneity of beliefs in the standard CAPM framework, different beliefs affect the market equilibrium returns. Detemple and Murthy (1994) prove that the market equilibrium interest rate itself is a function of agents' beliefs, weighted according to the fraction of total wealth held by the agents. Kraus and Smith (1989) argue that, even in the absence of new information about security payoffs, change in beliefs may move prices. Even if investors' probability beliefs about the assets' ultimate payoffs were correct, there would still be uncertainty due to the fact that investors have imperfect information about the endowments of the other investors. The fact itself that investors are imperfectly informed about each other creates and reinforces uncertainty and preserve heterogeneity of beliefs at equilibrium. This "market created risk" affects prices and equilibrium levels of returns. Furthermore, a burgeoning literature (Kim and Verrecchia (1991), Grundy and McNichols (1989) and Shalen (1993), Biais and Bossaerts (1998)) explicitly links heterogeneity of beliefs to trading volume and volatility. In general it finds a positive direct relationship between dispersion of beliefs and both volume and price volatility.

To date, however, the empirical findings to support such theories have been scarce in terms of the effects of heterogeneity of beliefs on either asset levels of returns or volume and volatility. The main reason is the lack of a good proxy for the dispersion of beliefs. Trading volume itself and open interest have been identified with dispersion of beliefs, but no direct evidence has been derived based on microlevel data.

With our dataset we can use the behavior of momentum and contrarian investors to directly construct a proxy for "market polarization" that gauges the dispersion of beliefs. This allows us to explicitly test how asset prices returns and trading volume and volatility are affected by the dispersion of beliefs. We find that dispersion of beliefs explains part of the variance in returns not accounted for by the standard asset pricing models. We also show that, while our measure of market polarization is directly related to trading volume and open interest, it has additional power to explain asset return variance. 
Our paper is organized as follows. Section II describes the data and our definitions of momentum and contrarian investing. Section III reports summary evidence about these key sub-groups. Section IV examines the cross-correlations and potential causality among different investor classes. Section V considers the contemporaneous relationship between flows and returns and describes our analysis of the inter-temporal variation on relative salience. Section VI concerns the dispersion of beliefs and the relation to the asset pricing model. Section VII concludes.

\section{Index Fund Data}

Despite the increasing importance of index fund investing in the U.S. over the past two decades, there is relatively little information about the scale, activity and type of investor accounts that comprise an index fund. This sample is particularly interesting, however, because investors in the fund have explicitly chosen an index fund as opposed to a managed fund

\section{II.1 Fund Description}

Fidelity provided us with anonymous individual account activity in their Spartan Market Index Fund over the years 1997 and 1998. The objective of the fund is to closely match the returns to the S\&P 500 Index while keeping management fees, transactions costs and other expenses to a minimum. Over the past five years, the fund has returned $27.51 \%$ per year compared to the S\&P 500's return over the period of $27.87 \%$. The fund has a short-term trading fee of $1 / 2 \%$ for redemptions that occur within 90 days, a minimum initial investment of $\$ 10,000$ and a minimum required balance of $\$ 5,000$. These minimums are less for a retirement account. The two years of our study were both banner years for the S\&P 500. It grew by $33 \%$ in 1997 and by $28.5 \%$ in 1998 . The fund also grew dramatically over the two-year period -- from \$1,597.5 million at the end of 1996 to $\$ 7,149.9$ at the end of 1998 growing by a factor of two, after the effect of the growth in share prices is taken into account.

\section{II.2 Data}

We have daily activity records for all accounts that existed or were formed in the two-year sample period. All individual identifying characteristics of these accounts were removed. We have absolutely no data on personal characteristics of the investors other than the account balances and 
trades. The accounts are only identified by type which we sorted into four general categories: Individual, Tax-Benefited, Fiduciary and Trust or Group. Table 1 describes our sample. After screening for various data errors (such as accounts with withdrawals that exceed balances) we have a total of 90,768 accounts. We have 259,616 transactions of which $83 \%$ are purchases of shares and $17 \%$ are share redemptions. The largest category of investor $(66,903)$ is the Tax-Benefited account -principally IRA and Keogh plans. Next is individual account $(16,185)$. We have a small number of Fiduciary accounts $(5,493)$ which include Executors, Guardianships and Trusts. The Group category $(2,179)$ includes Investment Clubs, Partnerships and other accounts that are held in the name of an association of some sort.

\section{II.3 Summary Measures}

Our data clearly suggest that investors in passively managed funds are themselves passive -they trade very little. The median fund investor trades once a year in our sample and the average number of transactions per account over the 505-day period is 2.86 . The number of transactions is slightly higher for taxable as opposed to tax exempt accounts. In our previous paper we examined evidence for seasonality in S\&P 500 fund flows and found very little. Despite the fact that the typical account has a single contribution per year, the date of that contribution varies across all months. In particular, there is no "turn-of-the-year" effect in our sample, no day of the week effect and no end of the month effect. ${ }^{1}$

How big are the investor accounts? Because accounts begin and end within the sample, determining an appropriate scale measure for the typical account is not trivial. We calculate the average running balance $[\mathrm{RB}]$ by taking the average number of shares held by an investor over the period for which the account is open. ${ }^{2}$ The average individual RB is 400 shares, or about $\$ 28,000$ to $\$ 36,000$,

\footnotetext{
${ }^{1}$ This result was surprising enough that we checked with Fidelity to determine whether this was consistent with their own experience -- it was.

${ }^{2}$ We construct $\mathrm{H}$ by weighting the number of shares $(\mathrm{N})$ an investor holds between the purchase date (b) of the shares and the sales date (s) of the shares, that is: $H_{i}=\sum_{t=b}^{s} N_{i, t}(s-b)$. We then divide this by the number of days the account is open in the period to calculate running balance. That is, the difference between first and last
} 
with the median individual account at less than half that. As a measure of activity in the account, we calculate turnover ratio $[\mathrm{T}]$ as the absolute sum of the number of share purchases and sales divided by the running balance. Thus, a perfectly passive investor who had 100 shares at the beginning of the period and held them through the end would have a turnover ratio of one. In Table 1, the median turnover ratio for all accounts is slightly greater than one. The mean is dramatically higher suggesting that some accounts have a lot of activity.

Table 1 also reports an Investor Profit Ratio. This is a measure of investor profits due to the timing of their flows in and out of the fund. It is not the standard time-weighted rate of return typically used to measure portfolio performance. The time-weighted rate of return would simply equal the return to the index fund over the period of the investor account's existence and would be unaffected by how much money was in the account at different times. As such, it would not provide a measure of timing skill relative to a meaningful alternative. ${ }^{3}$ Instead, we use a standard accrual method for profit calculation. The capital appreciation of each share purchased is tracked separately for the investor, and profits are defined as the accumulated growth in all share values at the termination of the account or the end of the sample period. This profit is scaled by the capitalization of the net value of share purchases and sales invested at the beginning of the sample period. In effect, we report timing profits by comparison to a benchmark buy and hold strategy, where we assume the investor could have placed all of his or her money in the fund at the beginning of the two-year period, as opposed to distributing the contributions throughout the period.

This is an imperfect measure, since it relies on certain assumptions that may be unrealistic. Among these assumptions is that the investor has the money to buy shares at the beginning of the sample period, rather than when shares were actually purchased. What we attribute to strategic delay in investment may simply be investor illiquidity. Because of this issue, we also considered scaling terminal share values by the gains to a dollar-cost-averaging strategy that effectively distributed net share

holding dates for investor i: $R B_{i}=\frac{H_{i}}{\max \left(t_{i}\right)-\min \left(t_{i}\right)}$.

${ }^{3}$ An alternative we considered as a measure of profitability is the internal rate of return on each account. This has been constructed by taking initial balance and contributions as negative flows and withdrawals and ending balance as positive flows, and then by scaling the IRR by the growth of the index over the period of the account's existence. Unfortunately, the negative intermediate cash flows led to many multiple solutions to the IRR, and thus we chose not 
purchases equally through the sample period. This however would not change the relative rankings of investors, but only the absolute value of the Profit Ratio. The second major limitation of the investor profit ratio is that many of the accounts in our database opened after the beginning of our sample period. Incoming investors may simply have switched from another S\&P index fund rather than cash. Given the high return to the S\&P in 1997, latecomers to the fund will typically have a low profit ratio.

Because the profit patio measure has limitations, we make no claim that it perfectly measures relative investment skill. Later in the paper we explicitly employ timing measures to capture relative timing skill, for example. Where we use it in the paper to measure relative skill, we attempt to control for the potential biases discussed above. It is reported in Table I simply to describe its distributional characteristics and not as an indication of skill across account type.

\section{Daily Momentum and Contrarian Strategies}

We use individual account activity to classify investors according to their conditional pattern of share purchases and redemptions. Our positive feedback traders (momentum investors) are reacting on a daily, as opposed to a weekly, monthly or annual basis by purchasing when the market rose and selling when the market fell in the previous trading session. Our negative feedback traders (contrarian investors) are characterized in exactly opposite fashion. They buy after a drop in the market and sell after a rise. In this respect, they behave like "profit-takers" -- a term used frequently in the financial press to characterize investors who sell after a market rise. Of course it is possible to define positive and negative feedback trading over much longer horizons. Indeed, for studies of momentum investing, for example, it would be useful to condition behavior on the market performance over previous weeks, months or years. Our definition of momentum investing is different from the way Grinblatt and Kellaharin (1998) apply the term in that profitable momentum strategies as documented empirically are cross-sectional and are based upon the past several months as opposed to days. In this paper, our choice of the daily horizon is based upon our analysis of aggregate index fund flows in Goetzmann and Massa (1998), where we found some evidence that, on average, index fund investors reacted negatively to the previous day's market drop. In addition, index fund daily flows are correlated to the movement 
of the market in a manner suggesting that S\&P 500 index fund investors may at times be salient to stock price formation.

In addition to classifying investors in terms of their strategies conditional upon preceding day returns, we also classify them in terms of their response to changes in the implied volatility of the S\&P 500. In our previous paper, we found some evidence for volatility timing behavior. In particular, both aggregate inflows and aggregate outflows were correlated to increase in implied volatility. We found this surprising, since it appeared inconsistent with mean-variance optimizing behavior. Our goal with the current data is to identify different classes of investors who react differently to risk. Risk-timing in general may be an interesting aspect of investor behavior that has yet only been examined in a limited manner. Bussey (1998) for example, finds that mutual fund managers may engage in successful volatility timing. Graham and Harvey (1996) find that market-timing newsletters have some ability to forecast market volatility. Market-timers conditioned their asset-allocation recommendations on what appear to be successful forecasts of market volatility. These results suggest that individual investor behavior may be conditioned upon risk.

\section{III.1 Methodology and Investor Types}

Our classification of investors as positive and negative feedback traders is based on a binomial test of the differences in proportions applied to daily investor inflows (and outflows) and the daily market return. We define a momentum investor as one whose frequency of share purchases following days after a market rise greater than one would expect given a random distribution of share purchases of the same number within the sample period. A contrarian investor is defined analogously as an investor who sells shares conditional upon an increase in the market on the previous day, and buys conditional on a market downturn. The null hypothesis for both types is that the ratio of purchase-days to non-purchase-days, conditional upon previous day's market direction, is equal to the unconditional ratio of up (or down) days for the market. Since investors trade relatively infrequently in our sample, we cannot employ the normal approximation to the binomial and thus, critical values for rejection of the null are given by summation of the binomial frequencies up to a probability level less than the critical value of $10 \%$ for a one-sided test. We apply this test to each investor's inflows and outflows separately. 
The same procedure is used to classify investors according to the change in implied volatility in the preceeding trading day. We obtain the implied volatility for S\&P 500 option contracts from the CBOT, calculated by inverting the Black-Scholes formula. We code days in terms of the percentage change in the implied volatility from the previous trading session. Thus we identify investors in terms of their reactions to changes in expectations about market risk. For both market return and volatility, we identify investors in terms of their associations with contemporaneous reactions as well. Both contrarians and momentum traders are therefore defined in terms of the reaction to the previous day returns/volatility.

Table 2 reports the classification of accounts according to whether they have positive or negative feedback tendencies. The top panel reports results for all accounts and the bottom panel restricts the analysis to accounts with eight or more transactions in the period. The distribution for inflows and outflows into individual accounts suggests that contrarian investors are slightly more common than momentum ones. Almost $25 \%$ of the accounts display a negative-feedback trading tendency, while only $12 \%$ display positive feedback characteristics. This is true across all four categories of accounts. This is consistent with Grinblatt and Kelaharin's findings that contrarians are more common in their sample than momentum investors. Notice that the proportion of undefined accounts is greater for outflows than for inflows. This is because outflows are relatively infrequent in our sample.

Accounts with more than eight transactions show a different tendency from the general population. While individual accounts with more than eight transactions have some tendency towards negative feedback, the other three groups appear to strongly favor positive feedback -- on balance more than $50 \%$ of the frequent traders appear to be positive feedback investors, vs. $37 \%$.

Table 2 also indicates that the individual accounts classified as significant volatility chasers is higher $(10.76 \%)$ than those classified as significant volatility avoiders $(6.78 \%)$ although the proportion who display positive and negative volatility-chasing in general is about equal.

\section{III.2 Consistency}

To test for the inter-temporal consistency of this timing behavior we again use an odds-ratio test based on a two by two table. We consider all accounts that existed over two sub-periods: 1/1/1997 to 
$31 / 12 / 1997$ and $1 / 1 / 1998$ to $31 / 12 / 1998$. For each period we use the proportion statistic described in the preceding section to identify investors as having either momentum or contrarian tendencies, where the median proportion measure is the dividing line between the two. We further restricted ourselves to accounts for which the probability level defined by the binomial test above exceeded $50 \%$ i.e. we only looks at those who were more likely than not to be a momentum or a contrarian investor. Because of the infrequency of sales in the sample, there are relatively few "sales contrarians" -- not enough to perform the test.

To test for consistency of behavior, we examine whether investors identified as momentum in the first period are more likely to be momentum investors in the second period. ${ }^{4}$ The values of the statistics (B) for the odds ratio test are significant for all classes except volatility momentum in sales and sales return and volatility contrarians. ${ }^{5}$ The results indicate that investor groups we identify typically display consistency over time. In particular, they show that daily return momentum investors repeat both when they are defined in terms of purchases and when they are defined in terms of sales. In contrast, volatility-conditioned activity does not seem consistent. Volatility momentum investors repeat only when defined in terms of purchases and not when defined in terms of sales. Contrarian investors always repeat, but only when defined in terms of purchases, while the number of observation is not sufficient to draw any statistically significant conclusion when they are defined in terms of sales.

\footnotetext{
${ }^{4}$ An odds ratio test is then applied to see if the accounts which have a behavior higher than median in the first period repeat themselves in the second period. In particular, the odds ratio statistic is $B=\ln \frac{M M * C C}{M C * C M}$ where $\mathrm{M}$ is the number of investors classified as momentum in both periods. CC is the number of investors classified as contrarian in both periods, $\mathrm{MC}$ is the number classified as momentum in the first and contrarian in the second and $\mathrm{CM}$ is the number of investors classified as contrarian in the first and momentum in the second. The null that the behavior does not repeat in the two periods corresponds to an odds ratio equal to 1 and the statistic is distributed normally as $N\left(1, \frac{1}{M M}+\frac{1}{C M}+\frac{1}{M C}+\frac{1}{C C}\right)$.

5 The test statistic values are:
}

\begin{tabular}{lcccc} 
& Purch. Momentum & Sales Momentum & Purch. Contrarians & Sales Contrarians \\
\cline { 2 - 5 } Investors reacting to return s & 6.4338 & 2.0048 & 11.2731 & $*$ \\
Investors reacting to volatility & 4.0556 & 1.6110 & 4.7423 & $*$
\end{tabular}




\section{III.3 Profitability}

One feature of models with rational momentum investors is that positive feedback trading is potentially profitable. Our data allow us to provide some evidence on this, using the measure of profitability described above. That is, profits are calculated as the terminal value of the sum of the inflows and outflows each accrued at the return on the index fund divided by the terminal value of a buy and hold strategy. This assumes the investor had all investable funds at the beginning of the sample period. We estimate profits for all the purchase and sale contrarian and momentum investors, and also define an additional class of investor -- thus who are "full momentum" or "full contrarian," i.e. investors who have greater than $50 \%$ probability of being both purchase and sale momentum investors and analogously, those who have greater than $50 \%$ probability of being both purchase and sale contrarians.

We also calculate profits for the rest of the market, that is the profits for all those who are neither contrarian nor momentum investors i.e. they have less than $50 \%$ chance of rejecting the null in favor of either typology. Table 4 reports the profitability for different classes. The profitability measure is problematic since longer investor "life" in the sample is likely to be correlated both with profitability as well as with momentum and contrarian significance. ${ }^{6}$ There is no obvious bias when comparing profitability of momentum investors versus contrarian investors, since they are both likely to be subject to the same selection criteria. Looking at the means, it appears that purchase contrarians, full contrarian and sales momentum contrarians earn significantly higher profits than the rest of the market. Purchase contrarians appear marginally profitable than purchase momentum investors. ${ }^{7}$ The most apparent differences are between purchase and sales momentum trades -- traders who tend to sell after a market drop appear to be more profitable than those who buy after a market rise. On balance, full contrarian traders seem more profitable that full momentum traders, although the latter category contains far too few observations for reliable inference.

\footnotetext{
${ }^{6}$ Our definition of momentum and contrarian depends upon being able to identify such behavior form a pattern of trades. For investors who trade only one or two times, we cannot identify them as either. The shorter the time period that the investor has been in the sample, the less the expected number of trades. This is likely to induce a positive correlation between momentum or cotrarian and profitability.

${ }^{7}$ Significance is calculated using a two-sample t-test assuming unequal variances and differing sample lengths.
} 
When the feed-back strategy is defined in terms of volatility, both sales and purchase momentum and contrarian variance-conditional strategies apparently deliver profits higher than the rest of the market. Also sales variance-momentum strategies deliver significantly higher payoffs than purchase variance-contrarians. However direct comparison of purchase variance-contrarians vs. purchase variance-momentum as well as comparison of sale variance-contrarians vs. sale variancemomentum do not deliver statistically significant results.

One problem with inferences based upon means in Table 4 is that mean and median values differ significantly. The skewness of the distributions violates the assumptions required for the t-test. In fact, the medians tell a different story than the means. The median values suggest that the typical contrarian, whether defined in terms of purchase, sales or both, is more profitable than the typical momentum trader. ${ }^{8}$ A Mann-Whitney test about differences in medians allows us to test whether the median investor profits for each category differs. ${ }^{9}$ Contrarians beat momentum investors for the categories of purchases, sales and full, however the latter is not significant. A direct comparison between full contrarians and full momentum investors is hampered by low sample size.

The medians test applied to variance strategies does not provide a clear ranking. Full variancecontrarians enjoy a statistically significant higher payoff than sales contrarians and sales contrarians have a return higher than purchase contrarians. Within the class of the variance-momentum investors, both sales momentum investors and full momentum investors have higher profits than purchase momentum investors. A comparison between classes shows that purchase variance-contrarian investors

\footnotetext{
8 We implemented a test of whether any of the strategies repeat in terms of profitability. Using the same odds ratio test as above, we found no evidence that successful conditional strategies in the first half of the sample were successful in the second half. Given the high correlation induced by clustering accounts that behave similarly, and our evidence that strategies repeat, even evidence of consistent profitability through time would be difficult to prove without econometric controls for cross-sectional correlation.

${ }^{9}$ The tests are based on a pairwise comparison of the medians of the profitability of the alternative strategies implemented by using a Mann-Whitney Test. The test is based on the statistics: $U=\operatorname{Min}\left\{T_{1}, T_{2}\right\}$ where: $T_{1}=n_{1} * n_{2}+\frac{n_{1} *\left(n_{1}+1\right)}{2}-R_{1}$ and $T_{2}=n_{1} * n_{2}-T_{1}$. Here $n_{1}$ and $n_{2}$ are the size of the two samples which are compared and $R_{1}$ is the sum of the ranks for the sample corresponding to $n_{1}$. The ranks are calculated on the pooled samples. We report the values of the statistics $\mathrm{z}$ defined as: $z=\frac{U-\mu_{u}}{\sigma_{u}}$, where, by applying the normal approximation, $\mu_{u}=\frac{n_{1} * n_{2}}{2}$ and $\sigma_{u}=\sqrt{\frac{n_{1} * n_{2} *\left(n_{1}+n_{2}+1\right)}{12}}$.
} 
are more profitable than purchase variance-momentum investors and that sales variance-momentum investors are more profitable than sales variance-contrarians. Also full momentum investors are significantly more profitable than full contrarian investors.

This last result may explain our earlier results (Goetzmann and Massa 1999), which suggested the presence of volatility timing in the aggregate flows of index funds. If such strategies are profitable, this may motivate their use. To correctly evaluate the attractiveness of such strategies, however, a riskadjustment -- at least a Sharpe ratio -- is clearly necessary. Given the limited information provided by profitability measures, we have not implemented such a risk adjustment.

\section{Internal Dynamics Among Investor Classes}

One way of assessing the role played by the different classes of investors is to explicitly test for causality among them. If some investor classes are prone to herding and others are "first-movers," we might expect the latter to Granger-cause the former. On the other hand, no Granger causation does not imply the complete lack of causality. We found in previous work that most of the effects between flows and S\&P returns are contemporaneous (Goetzmann and Massa 1999). The contemporaneous relationship between classes of investors and market returns will be explicitly addressed in the next section.

To test for causality, we estimate a standard Granger tests applied to the following VAR specification:

$$
\text { Flows }_{t}=\alpha+\gamma \text { Flows }_{t-1}+\varepsilon_{t}
$$

where Flows is the vector of investor class flows in and out the index fund (purchases and sales). The flows are defined in terms of number of shares purchased/sold and are aggregated into different groups depending on the momentum and contrarian identification of the investors. Table 5 reports the probability values of the joint significance of the lagged values of the variables whose ability to Grangercause the dependent variable is to be tested. The VAR is estimated with 2 and 5 lags.

Note that there is virtually no evidence of causality across share purchases of investor classes, although there appears to be some inertia for the main investor class and for momentum investors. In contrast, causality goes both directions for all three groups for share sales. If there is any cross-group feedback it appears to be only in selling activity -- herd behavior appears to be related to sales more 
than purchases and it is not clear that division into three classes makes much difference to this analysis. In the second panel of the table, volatility strategies are examined. Note that Granger-causality appears to go both ways when investors are grouped on the basis of sales. Selling appears to be correlated across investors groups both at both forward and backwards lags. There is, however, some evidence

in the second panel of Table 5 that differentiating by volatility strategies might be useful. Volatility momentum investors appear to strongly cause volatility contrarians -- thus risk-chases lead risk-averters in our sample.

\section{Estimating the Investor Class Relationship to Returns}

A key issue in behavioral finance is the extent to which systematic behavior -- rational or otherwise -- affects prices. We will consider the role played by different classes of investors by looking at it from three different perspectives. From previous evidence (Goetzmann and Massa 1999) we know that flows affects returns and that there is a strong contemporaneous relationship between flows and returns. Therefore, we first consider the relationship between contemporaneous returns and flows, disaggregated by classes of investors, to see whether all the different classes are significant in terms of returns. Then we quantify the impact of each single class relative to the other classes.

\section{V.1 Contemporaneous Regressions of Returns on Flows}

In this section, we consider the effect on asset prices of the purchase and sales flows of different index fund classes on asset prices. First, we estimate regressions of market returns on the flows by the portfolios of the different classes. The functional specification estimated is:

$$
R_{t}=\alpha+\beta \text { Flows }_{t}+\varepsilon_{t}
$$

where $R_{t}$ are the returns on the SP500 index, while Flows $s_{t}$ are the flows (inflows and outflows) of portfolios made of the purchases (inflows) and sales (outflows) of the fund units by specified categories of investors (momentum and contrarians). A separate regression is estimated for each category. Given that market trends are endogeneous to the procedure for identifying investor class, we identify classes and test the effects over two separate periods. Contrarians and momentum investors are identified in the period 01/01/1997-31/12/1997 and then regressions of S\&P 500 returns on investor-class flow 
portfolios over the second period, 01/01/1998-31/12/1998. We also report results using the same period for indentification and estimation to get an idea of the magnitude of the endogeneity problem. The results are reported in Table 5. They show that $\mathrm{S} \& \mathrm{P}$ returns may be correlated to the decisions by active timers. While we might expect momentum investor decisions to be correlated to S\&P 500 returns (especially when classes are defined over the same period when the regressions are performed) we also find that sales contrarian flows are positively related to the market. In other words, timer activity -- both momentum and contrarian -- correlates to positive market moves in our sample. With regard to strategies defined in terms of volatility, it appears that purchases by investors who tend to sell on higher variance have a positive relation to the market, and sales by "risk-chasers" are negatively correlated to the market. One limitation of the regressions is that the coefficients are fixed over the timeperiod of study. If the decisions of contrarians were salient at different times, we would not pick this up in the current specification.

\section{V.2 Sharpe Regressions}

In order to examine the inter-temporal behavior of the correlation between timer decisions and the S\&P 500, we allow coefficients to vary over 90-day intervals. To simplify the interpretation of these coefficients and to be able to quantify the impact of each class of investors relative to the others, we use a technique similar to Sharpe (1992), Lo and MacKinlay (1995), Fung and Hsieh (1997) and Brown, Goetzmann and Park (1998) to identify a maximally correlated portfolio. The intuition is that there exist weights on the class flows that allow the construction of a portfolio that is maximally correlated to S\&P 500 returns, and the composition of that portfolio is allowed to change through time. Portfolios are thus constructed by minimizing the squared residual error of the vector of returns of the S\&P500 index by using investors' purchases and sales as explanatory variables, subject to the constraint that the weights in the portfolios are positive and add up to one. In particular, we estimate:

$$
\begin{gathered}
\operatorname{Min}_{w_{t}}\left[R_{t}-\mathbf{w}_{\mathbf{t}} \mathbf{F l o w}_{t}\right]^{2} \\
\text { s.t.: } \mathbf{w}_{\mathbf{t}} * \mathbf{e}=1 \\
w_{i t} \geq 0 \forall i
\end{gathered}
$$


where $\mathbf{w}_{\mathbf{t}}$ is a vector of weights of size equal to the number of components of the portfolio of flows, Flow $_{t}$ is vector of length i comprised of flows for day $t$ for class purchase or sale $i$ (purchases or sales of shares by contrarians on day $t$, purchases or sales by the rest of the market, or purchases or sales by momentum investors) and $\mathbf{e}$ is a vector of ones. ${ }^{10}$

The normal interpretation of the coefficients in the Sharpe estimation procedure is that they are positive portfolio weights applied to investable assets. In this case, however, the flows are not assets. They instead are weights on the dollar flows, and thus weights on investor classes. The weights are reported for the purchases and sales separately as well as for the net purchases. Furthermore, the impact of the different strategies are separately estimated for momentum and contrarian investors defined in terms of reaction to returns as opposed to reaction to volatility. To avoid endogeneity problems, classification is done in the period 01/01/1997-31/12/1998 and the estimation is performed over 01/01/1998-31/12/1998.

Considering the static results (Table 6), we see that, in terms of net purchases, momentum investors play the major role. Because momentum investors have the highest weights, we cannot necessarily interpret this evidence about which investor class most strongly influence returns. Either momentum investor decisions influence stock returns or vice-versa or both. Since we know momentum investors by definition chase flows, we may simply be identifying intra-day momentum investing. Indeed, even if we have defined the strategies in terms of reaction to previous day either return or volatility, still it is possible that previous-day trend chasers are also same-day trend chasers. Therefore the correlation with today returns would only be due to trend-chasing behavior.

To address the question of whether the momentum investor correlation to contemporaneous return is largely due to trend-chasers, we test whether the set of momentum investors overlaps significantly with the set of investors who display contemporaneous positive correlation in returns in the initial identification period. To do this, we calculate the ratio between the number of investors in the first period who react both to past and contemporaneous returns and the total number of investors who either react to past or contemporaneous return. The results do not favor the hypothesis of trend chasing behavior. There is not a big overlap in the sample of momentum investors defined alternately on

\footnotetext{
${ }^{10}$ Due to the large difference in magnitude between returns and flows, a constant scaling factor is also used to
} 
contemporaneous or lagged returns. If we select the momentum investors as the ones who react to returns by selling, there are only $7.3 \%$ who are reacting to both past and contemporaneous returns. If, on the other hand, we define the momentum investors in terms of purchases, there are only $7.9 \%$ who react to both past and contemporaneous returns. Analogously, if we define the contrarians in terms of sales, there are $19.92 \%$ who are reacting to both past and contemporaneous returns, while if we define the contrarians in terms of purchases there are $14.45 \%$ who are reacting to both past and contemporaneous returns.

Also, a more detailed look at the different components, in terms of purchases and sales (Table 6, III Specification), shows that the single most important class of agents are the "volatility contrarian purchasers".

The dynamic estimation is a series of rolling regressions with overlapping 90-day windows. Figures 1 and 2 plot the values of the weights for the different classes. Weights are reported for net purchases (Figure 1) as well as for sales and purchases separately considered (Figure 2). The net flows suggest that both return momentum and volatility momentum investors represent the greatest weight in the maximally correlated portfolio. It is, however, interesting to note how the weight on contrarian investors increases through the sample. It is reasonable to expect that macro-economic factors or even market price levels could play a role in the changing salience of various groups. The financial press often reports that drops in a bull market are regarded as buying opportunities by investors. Over our period of study, the steady rise in the market may have provided just such opportunities. If we have data from a bear market period, the weights may have differed dramatically. The important message of both graphs is that the marginal investor, if that is indeed who we are identifying econometrically -- may vary substantially through time. While momentum investor decisions seem to predominate in terms of explanatory power, contrarian behavior is important at times as well.

Regardless of which of the two groups has the highest weight at any given time, weights are highest on the two systematic classes, volatility momentum and volatility contrarian are higher than on the undefined group. For fixed weights over the period variance avoiders have a higher weight than risk-chasers, however when weights are allowed to vary, volatility momentum traders weights are 
generally above those of the risk-avoiders. If we interpret the volatility momentum investors as those more likely to be speculating on market dynamics, they appear to be more salient.

\section{V.3 Identifying behavioral factors}

The next question is: if investors' strategies are correlated to asset returns, is it possible to use investor flows to construct "behavioral factors" that span asset returns? To do this we resort to the standard Fama-MacBeth [FM] two-stage time-series cross-section test, applied to daily return timeseries. We estimate two sets of factors: the standard market factors derived from market returns and some "behavioral" factors estimated from the flows of the investors in the index fund. We then compare the explanatory power of the two types of factors. We test two hypotheses. First, if flows affect returns, we would expect that the behavioral factors have an explanatory power at least as high as the one based on market factors. Second, the behavioral factors based on the class of marginal investors should have the highest explanatory power, beating the market factors. We will use the time-series of $\mathrm{R}^{2}$ from the daily cross-sectional FM regressions derived from the different factor specifications as a basis for our comparison.

First, we estimate factor loadings for a set of portfolios formed from both stock returns and investors' flows (behavioral factors) using a four-factor latent variable model. In the former case, we consider the regularly-traded individual securities in the U.S. market. The factors are extracted and loadings estimated using leading rolling windows. In particular, we take the 560 stocks in the CRSP database that have been consecutively traded in the two-year period 1997-1998 with no missing observations. We then create 20 portfolios each containing 28 stocks, ranked by market capitalization. This allows us to cover virtually all the stocks contained in the S\&P500 which are also regularly traded.

In the case of the behavioral factors, we consider the daily flows into the fund (purchases and sales). The construction of the flows is particularly tricky, as aggregation of all the flows from all the investors would yield very low explanatory power. The goal of our exercise is to identify the class of investors whose behavior provides the best way to explain predict future differences in returns. We therefore consider various combinations of investors, aggregated in terms of either their investment characteristics or trading behavior. The trading behavior is defined in terms of the class of investors we identified before: momentum and contrarian investors. In particular, we consider two specifications: one 
where strategies are broken down in terms of their definition as reaction to returns and volatility (contrarian and momentum) and another where strategies are broken down in terms of the type of action undertaken (purchases, sales, net purchases).

In the first specification we use four "portfolios of flows": return contrarians, return momentum investors, volatility contrarians and volatility momentum investors. Each single portfolio is composed of the purchases and sales of the investors belonging to the specific category, one factor for each way of identifying them. For example, the portfolio of return contrarians is made of four components: the vector of the purchases of the contrarian investors identified as contrarians on the basis of their sales, the vector of the purchases of the contrarian investors identified as contrarians on the basis of their purchases, the vector of the sales of the contrarian investors identified as contrarians on the basis of their sales and the vector of the purchases of the contrarian investors identified as contrarians on the basis of their purchases.

In a second specification each one of the portfolios is composed of the transactions (either purchases, or sales or net purchases) of the investors who strategically react to either return or volatility. They are purchases of return investors, purchases of volatility investors, sales of return investors, sales of volatility investors, net purchases (purchases minus sales) of return investors and net purchases of volatility investors.

For example the portfolio of the purchases of return investors is made of four factors: the purchases of the return contrarians identified as contrarians on the basis of their purchases, the purchases of the return contrarians identified as contrarians on the basis of their sales, the purchases of the return momentum investors identified as momentum investors on the basis of their purchases, the purchases of the return momentum investors identified as momentum investors on the basis of their sales.

We consider two alternative specifications, one with four factors and one with eight factors. In the first, we directly compare the explanatory power of the four factors extracted from past returns to the ones extracted from investor flows. In the second, we consider the four factors extracted from past returns plus the four factors based on the investors' flows orthogonalized by regressing them on the first four factors. In this case, we test whether the factors derived from investors' flows have an additional incremental explanatory power to the one already latent in the market returns. 
We estimate loadings for each portfolio and portfolio weights via a principal component analysis performed on over-lapping 90 days windows through the sample period. Given that we are dealing with daily data with potential lead-lag effects due to asynchronous trading, we apply the Dimson-Marsh correction using two days of leads and lags.

The factor extraction and the estimation of the betas is updated each day in the sample, following the initial 90-day estimation period. Thus, betas are allowed to vary through time. Given that we need a 90-day rolling window to estimate the factors, our sample consists of 412 observations (March 1997-December 1998). This generates sets of betas that are then used as explanatory variables in the second step of the procedure. Presumably, the latent-variable model will capture the relevant factors driving the cross-section of returns in the preceding 90-day window. If, for example, these true factors were a rotation of the Fama-French factors they should be captured in the first stage. If they are well estimated, they we would expect their loadings to explain cross-sectional dispersion in returns in the following period.

The standard Fama-MacBeth analysis only focuses on the regression of the day following the estimation period. But with daily data there can be some problem of stability of the estimated beta and additional measurement error induced by the Dimson-Marsh correction. Furthermore, given that we found evidence that flows affect returns mostly through contemporaneous correlation (Goetzmann and Massa 1999), it is plausible to think that behavioral factors based on flows should have explanatory power only in the very short run (same day, following day). Therefore, for a robustness check, we repeat the same experiment for several different time horizons: that is the next 5, 10, 15, 20 and 40 days following the estimation period ${ }^{11}$. Given that all the results agree, we will report only the standard one based on time $\mathrm{t}$.

In stage 2, we regress portfolio returns on betas each day following the estimation period and save the resulting $R^{2}$. We report the mean $R^{2}$ and the $\mathrm{P}$-values of the test that the means of the $\mathrm{R}^{2}$ of the regressions based on behavioral factors are statistically different from the means of the $\mathrm{R}^{2}$ estimated using only past market factors.

\footnotetext{
${ }^{11}$ The results are available upon request from the authors.
} 
The results, reported in Table 7, suggest that flows explain returns at least as well as past return-derived factors . In all the different specifications, the results holds for both the case when strategies are broken down in terms of reaction to return/volatility and the case when strategies are defined in terms of the type of action undertaken. In most cases, there is no statistical difference between market-based factors and flow-based factors.

Second it is possible to identify portfolios of flows which have the highest explanatory power. In particular, among the different behavioral components, it seems that the portfolios of flows originated by the investors who react to volatility through purchases are the ones which have the greatest explanatory power. In particular, among them, volatility contrarians play a prominent role.

These results have several important implications. First, they provide evidence that non-price related factors are as good as predictors of future returns as the standard return based factors. Here, it is worth stressing that we are dealing with flows expressed in units of the index funds and not in monetary value. Therefore, they are completely devoid of any price-related informational content.

Second, in terms of asset pricing, this implies that a new reformulation of pricing, based on different models where flows play a role may be desirable. Standard asset pricing models assume away any influence of flows postulating an infinitely elastic demand function. Maybe some of the assumptions behind the equilibrium models have to be reconsidered.

Also, these results provide a justification for the rising industry of sellers of datasets based on flows. But, if it is possible to improve the predictability of future returns on the basis of past flows, there must be room for speculation. In this case, it is not clear why this has not yet been arbitraged away and if we are facing a new market "irregularity" or if the improvements in forecasting ability are within the transaction costs.

Our results are also consistent with the possibility that there is an omitted variable from the asset pricing model that is correlated to investors' flows. Had we used pre-specified factors, for example, we might have simply failed to include the relevant ones. Although designed to maximize explanatory power in-sample, the latent variable model itself could fail if the factor realizations occurred at a low frequency and 90 day windows are of insufficient length for identification of relevant systematic variables. In fact, the omitted variable could be correlated to the instrument based on flows. In the next section, we consider a candidate for a key omitted variable -- dispersion of beliefs. 


\section{Factor Model Performance and Dispersion of Investor Beliefs}

Dispersion of beliefs plays an important role in a number of asset pricing models. Classic single-period pricing models typically either require common expectations about the first and second moments of asset returns, or the existence of a single risk-averse investor without credit contraints who sets prices higher than those disagreed upon by other investors in the economy. We expect an equilibrium model to be associated with a parsimonious set of priced factors and common expectations about risk premia. When the necessary conditions of common expectations are not satisfied, we might then expect the pricing model to perform poorly. In fact, Williams (1977) formalizes this in a model. He shows that, if we relax the assumption of homogeneity of beliefs, the standard CAPM can be written as:

$$
R_{t}=\beta\left(r_{m t}-r_{f t}\right)+\sum_{n=1}^{N} \Omega_{n t}+\varepsilon_{t}+\eta_{t}
$$

where $N$ is the number of assets, $\mathrm{R}_{\mathrm{t}}$ is the excess return over the riskless asset at time $t, \mathrm{r}_{\mathrm{mt}}$ is the return on the market portfolio and $r_{\mathrm{f}}$ is the return on the riskless asset, still at time $t . \Omega_{\mathrm{nt}}$ is a factor that accounts for average investors' preferences (indirect utility functions) and the residual covariances between returns on the risky securities and changes in investors' average subjective mean for security $n$ at time $t . \eta_{\mathrm{t}}$ is an additional source of uncertainty in the residual due to heterogeneity of beliefs which exhibit serial correlation. The main difference with respect to the standard asset pricing models lies in the

additional terms: $\sum_{n=1}^{N} \Omega_{n t}+\eta_{t}$. In particular the role played by investors' beliefs is captured by the $\Omega_{\mathrm{nt}}$ that represents the "correlation between residual returns and adjustments in investors' subjective expectations of the unknown mean return for each $n t h$ risky security". A direct way to test this model is to determine whether instruments for subjective expectations affect the fit of the standard asset pricing model. If momentum and contrarian investors have different expectations about future market returns they may provide an econometric basis for estimating the magnitude of dispersion in beliefs and in turn provide an instrument to test the pricing model.

In Goetzmann and Massa (1998), we use as an instrument for belief dispersion the sum of the absolute value of inflows and outflows from three Fidelity index funds. The logic of this measure was 
that when both inflows and outflows of the funds are high this indicates disagreement among investors about the prospects of the market. Our problem with the aggregated fows was that we could not identify them with different investor classes. With the current data we can now separate the inflows and outflows by investor classes. In this section, we construct measures of belief dispersion across momentum and contrarian investor classes and then relate this empirically to the relative performance of the asset pricing model. We examine the relationship between belief dispersion and the ability of a standard factor model to explain cross-sectional differences in equity returns. We find some evidence to suggest that periods of high dispersion in beliefs are associated with poor performance in the pricing model. We conjecture that this may be due to either periods of "breakdown" in the asset pricing model, or to a common correlation of both beliefs and residual risk to an unspecified variable.

\section{VI.1 Dispersion variables}

While actual beliefs are difficult to observe empirically, two variables have been used in the literature as proxies, among them are open interest in options (indicative of agents possibly agreeing to disagree about the prospects of the underlying security) and volume of trade (since every trade is by definition two-sided). Our dataset allows us to define a different measure. We proxy for dispersion of beliefs about the S\&P 500 by the absolute value of the difference between contrarian and momentum investor flows. In our earlier paper, we found that a measure of belief dispersion correlated well to the two proxies above, as well as to a measure of analyst disagreements, taken from timing newsletter forecasts. The current data allow us another potentially useful metric of belief dispersion.

Given that contrarian and momentum investors are in some sense "polar" we define the difference in their flows as measure of "market polarization." We regard this as a measure of dispersion in beliefs across traders we know to have systematic differences in their return-conditional behavior. One natural question is whether our measure of market polarization correlates with the standard measures of market uncertainty (implied volatility) and dispersion of beliefs (open interest and trading volume). To test this, we regress the market polarization on implied volatility, trading volume and open interest on the futures contracts written on the S\&P500 index. The results show a strong correlation between market polarization and the standard proxies for dispersion of beliefs (open interest and trading 
volume), with $t$ statistics greater than 3. ${ }^{12}$ No correlation, however, is found between market polarization and implied volatility. This fits with Prabhala (1998) who pins down open interest as a measure of dispersion of beliefs and implied volatility as a measure of market uncertainty, orthogonal one to the other.

The next step is to see test if there is a correlation between the explanatory power of standard asset pricing models our measure of market polarization. In particular, we expect that the explanatory power of pricing models that do not account for dispersion of beliefs should be the lower when the market is more polarized. That is, the explanatory power of the standard asset pricing framework should drop on days when the dispersion of beliefs is greater. In short a model that does not account for dispersion of beliefs is misspecified. We can therefore directly test whether our measure of market polarization increases the explanatory power of the standard asset pricing model and whether it has any explanatory power additional to the one of the contained in the standard factors.

\section{VI.2 Methodology}

In order to test this conjecture, we carry out two types of tests. First, we directly test whether adding our measures of market polarization increases the explanatory power of the cross sectional second stage previously of the before specified Fama-MacBeth [FM] estimation. Also we add a third stage to the FM procedure in which we regress our measure of belief dispersion on the time-series of the residuals from the daily cross-sectional FM regressions. Then we see if the dispersion of beliefs explain the residuals. If the beliefs condition the explanatory power of the standard asset pricing model, we expect to find that our measure of market polarization adds significant explanatory power.

In particular, in the first case we estimate a model based on 12 factors: four extracted from past returns, four based on the investors' flows orthogonalized by regressing them on the first four factors (behavioral factors) and four factors based on the dispersion of beliefs. We report the adjusted $\mathrm{R}^{2}$ as well as P-values of the test whether the means of the $\mathrm{R}^{2}$ of the regressions without the factors based on dispersion of beliefs are statistically different from the means of the adjusted $\mathrm{R}^{2}$ estimated using only the factors based on past returns and behavioral factors. Dispersion of beliefs are constructed as the

\footnotetext{
${ }^{12}$ Not reported but available upon request from the authors.
} 
absolute differences between purchases of contrarian and momentum investors, both defined in terms of return and volatility (return-based polarization of purchases and volatility-based polarization of purchases), as well as the absolute differences between sales of contrarian and momentum investors, both defined in terms of return and volatility (return-based polarization of sales and volatility-based polarization of sales).

The second approach, is based on the direct regression of our measure of belief dispersion on the time-series of the residuals from the daily cross-sectional FM regressions. In particular, we estimate:

$$
\operatorname{Re} s_{t}=\alpha+\sum_{k=1}^{K} \beta_{k} D B_{k t}+\varepsilon_{t}
$$

where Res $_{\mathrm{t}}$ is the residual from the second stage of the Fama-MacBeth procedure computed using 8 factors: four extracted from past returns (standard market factors), four based on the investors' flows orthogonalized by regressing them on the first four factors (behavioral factors) and $\mathrm{DB}_{\mathrm{kt}}$ are our measures of market polarization as defined before.

Dispersion of beliefs should explain the residuals on days when there is little is cross-sectional dispersion in returns on the size portfolios that is correlated to factor loadings. These are the cases where price fluctuations more diverge from the fundamentals and are subject to changes in market sentiment. On the other hand, dispersion of beliefs will have a low explanatory power in the days when all the security portfolios tend to move together on a given day, or when the cross-sectional variation is not well-explained by the factor model. In the latter case, this might be interpreted as a case in which either non-systematic factors spread returns -- something not expected if the pricing model is well specified and estimated -- or when idiosyncratic shocks spread returns.

\section{VI.3 Results of the FM Test}

The results, reported in Table 8 for the first type of test, show a strong and significant increase in the explanatory power of the regression due to the addition of the factors based on dispersion of beliefs. Furthermore, we find that the measure of dispersion of beliefs with the highest explanatory power is the one based on the different purchasing behavior of the investors whose strategies are defined in terms of reaction to market volatility (Tables 9 and 10). This holds for all specifications. One interpretation is 
that the factor constructed from flows of groups with polar attitudes towards market risk appears salient.

Finally we examine the correlation between the explanatory power of the standard FM model and dispersion of beliefs. In particular we estimate:

$$
R_{t}^{2}=\alpha+\gamma M P I_{t}+\delta M P O_{t}+\varepsilon_{t}
$$

where $\mathrm{R}_{t}^{2}$ is the average adjusted $\mathrm{R}^{2}$ of the cross-section regression of the stock returns on the on the pre-estimated betas. $\mathrm{MPI}_{\mathrm{t}}$ and $\mathrm{MPO}_{\mathrm{t}}$ represent our measures of market dispersion of beliefs or "market polarization." In particular, $\mathrm{MPI}_{\mathrm{t}}$ is the absolute difference between the purchases of momentum and contrarian investors, while $\mathrm{MPO}_{\mathrm{t}}$ is the absolute difference between the sales of the momentum and contrarian investors ${ }^{13}$.

The estimation is carried out using GMM, with Newey-West correction on the variancecovariance matrix based on a five lag autocorrelation structure. This is done in order to capture weekly effects. Instruments are used to correct for errors-in-variables and measurement problems ${ }^{14}$. Three different specifications are considered: where the measures of dispersion of beliefs based on purchases and sales are jointly considered and the cases where they are separately used.

The results, reported in Table 11, for the whole period, show a strong and significant negative relationship between explanatory power in the FM regression and measures of dispersion of beliefs. This fits with our earlier results suggesting that not only does dispersion of belief significantly increase the explanatory power of the FM regressions and spread returns, but also it does this exactly at the times where the standard factors provide a worse fit.

All these results seem to suggest that it is possible to use the trading behavior of contrarian and momentum investors to create indexes of market polarization. These indexes are related to the standard measures of dispersion of beliefs and help to explain variation in asset returns otherwise unaccounted for by the standard factor pricing models. They also suggest that they capture additional information not contained in the standard measures of dispersion of beliefs.

\footnotetext{
${ }^{13}$ Both measures are standardized by dividing them, respectively, by the sum of purchases or the sum of sales.

${ }^{14}$ The choice of the instruments has been based on Hansen's over-identification criterion. The instruments are: time dummies, a constant, dividend yield and yields on corporate bonds (based on Merril Lynch Index).
} 


\section{Conclusion}

We used a two-year panel of individual accounts in an S\&P 500 index mutual fund to examine the trading and investment behavior of more than 130,000 investors who have chosen a low-cost, passively managed vehicle for savings. This allows us to characterize investors' heterogeneity in terms of momentum and contrarian investment patterns. In particular, we have found positive feedback traders or momentum investors, as well as profit-takers or contrarians and tested the consistency and profitability of their strategies over time. We find evidence for behavioral consistency within our sample, despite the fact that most investors in the index fund trade very little. We also find some evidence of differences in profitability between momentum vs. contrarian investors with the typical daily contrarian investor profiting more from trades that the typical daily momentum investor.

The flows of different classes of investors allow us to examine which group displays the highest correlation between fund flows and market moves. Momentum investors are most highly correlated with the S\&P 500 returns. This is consistent with the hypothesis that they are the salient investors in the price-formation process of the S\&P 500. We cannot categorically reject the hypothesis that they are chasing returns intra-day, however we do not find evidence in favor of that explanation.

We develop a framework for examining behavioral factors in terms of classic empirical asset pricing models. Although we have insufficient time-series data to determine whether behavioral factors command positive risk premia, loadings on behavioral factors appear to spread returns out of sample. In fact, behavioral factors loadings perform well against a benchmark of loadings on latent variables extracted from the covariance matrix of stock returns themselves.

Finally, we examine the empirical relation between the dispersion of investor beliefs about the market and the explanatory power of the asset pricing model. We find that the model performs poorly when beliefs are most dispersed. This is consistent with the existence of an omitted factor correlated to belief dispersion and also with homogeneous beliefs being necessary to sustain the pricing model. 


\section{References}

Balduzzi P., G. Bertola, S. Foresi,1995, " Asset Price Dynamics and Infrequent Feedback Trades" Journal of Finance, Vol. 50, No. 5. (Dec.), pp. 1747-1766.

Barber B. and T. Odean, 1999, "Boys will be boys: gender, overconfidence and common stock investment", W.P. University of California at Davis

Barberis N., A. Shleifer and R.Visny, 1998, " A model of Investor Sentiment," Working Paper, Havard Economics Department, 1998.

Biais B. and P. Bossaerts, 1999, “Asset prices and trading volume in a beauty contest”, The Review of Economic Studies, 65, 307-340.

Bussey J. 1998, “ Volatility Timing in mutual funds: evidence from daily returns”, N.Y.U. Stern Business School, Mimeo.

Bikhchandani S., D. Hirshleifer, I. Welch, "A Theory of Fads, Fashion, Custom, and Cultural Change as Informational Cascades," The Journal of Political Economy, Vol. 100, No. 5. (Oct.), pp. 992-1026.

Brown S. J., W. N. Goetzmann and J. Park, 1998,"Hedge funds and the Asian Currency Crisis of 1997," NBER Working Paper.

Campbell J., Grossman S. and J. Wang., 1992 "Trading volume and serial correlations in stock returns", NBER Working Paper \#4193

Chan L. and J. Lakonishok, 1995, "The Behavior of Stock Prices Around Institutional Trades", Journal of Finance, 1147-74.

Chan L. and J. Lakonishok, 1993, "Institutional Trades and Intraday Stock Price Behavior", Journal of Financial Economics, 33(2), 173-99.

Chan L., Jegadeesh N. and J. Lakonishok, 1996, "Momentum strategies”, Journal of Finance, 51(5), 1681-1711.

Chevalier J. and G. Ellison, August 1995, "Risk taking by mutual funds as a response to incentives", NBER Working Paper \#5234.

Conrad J. and G. Kaul, 1998, "An anatomy of trading strategies", The Review of Financial Studies, 11(3), 489-519. 
Daniel K., D. Hirshleifer and A. Subrahmanyam, 1998, "A theory of Over-confidence, self-Attribution and Security Market Over and Under reactions," working paper, UCLA.

De Bondt W. F. M. and R. Thaler, 1985, "Does the Stock Market Overreact?" Journal of Finance, Vol. 40, No. 3, (Jul), pp. 793-805.

De-Long J. B., A. Shleifer, L. H. Summers and R. J. Waldmann, 1990, "Positive Feedback Investment Strategies and Destabilizing Rational Speculation”, Journal of Finance, 45(2), 379-395.

Detemple J. and S. Murthy, 1994, "Intertemporal asset pricing with heterogeneous beliefs", Journal of Economic Theory, 62, 294-320.

Ferson W. and R. Schadt, 1995, "Measuring Fund Strategy and Performance in Changing Economic Conditions", Journal of Finance

Ferson W. and V. A. Warther, 1995, "Evaluating Fund Performance in a Dynamic Market", Financial Analysts Journal.

Froot K.A., O'Connell P.G.J. and M. Seasholes, (1998), "The portfolio flows of international investors, I', NBER Working Paper, \# 6687.

Fung, W. and D. Hsieh, 1998, "Empirical characteristics of dynamic trading strategies: The case of hedge funds," Review of Financial Studies 10: (2) 275-302 .

Garry M. and W. Goetzmann, 1986, “Does de-listing from the S\&P500 affect stock price?”,

Financial Analysts Journal, 42(2) 64-69.

Goetzmann W. and M. Massa (1999) "Index funds and stock market growth", Mimeo, Yale University.

Gompers P. and A. Metric, 1998, "How re Large Institutions Different From Other Investors? Why do These Differences Matter?" NBER Working Paper.

Graham J.R and C., R.Harvey (1996) "Market Timing Ability and Volatility Implied in Investment Newsletters' Asset Allocation Recommendations “ Journal of Financial Economics, 42(3), 397-421.

Graham J. R. (1998) "Herding among Investment Newsletters: Theory and Evidence", Journal of Finance 54(1), 237-268.

Grinblatt M., Titman, S. and R. Wermers, 1995, “ Momentum Investment Strategies, Portfolio Performance, and Herding: A Study of Mutual Fund Behavior", American-Economic-Review; 85(5), 1088-1105. 
Grinblatt M. and M. Keloharju, 1999, “ Distance bias, language bias and investors sophistication: results from Finland", Mimeo UCLA

Grinblatt M. and M. Keloharju, 1999, “What makes investors trade?”, Mimeo UCLA

Grinblatt M. and M. Keloharju, 1998, “ The investment behavior and performances of various investortypes: A study of Finland's unique data set”, Journal of Financial Economics, forthcoming

Grossman S., 1995, "Dynamic asset allocation and the informational efficiency of the markets", Journal of Finance, 50, 773-787.

Grundy B.D. and M. McNichols, 1989, “ Trade and the revelation of information through prices and direct disclosure", The Review of Financial Studies, 2, 495-526.

Hirshleifer D., A. Subrahmanyam, S. Titman, 1994, "Security Analysis and Trading Patterns when Some Investors Receive Information Before Others," Journal of Finance, Vol. 49, No. 5. (Dec), pp. 1665-1698.

Holthausen R.W., Leftwich R.W. and Mayers D., 1990, "Large Block Transactions, the Speed of Response, and Temprary and Permanent Stock Price Effects", Journal of Financial Economics, 26(1), 71-95.

Hong H. and J. Stein, 1999, "A Unified Theory of Underreaction, Momentum Trading and Overreaction in Asset Markets," Forthcoming, Journal of Finance.

Jeegadesh N. and S. Titman, 1993, "Returns to buying winners and losers, implications for stock market efficiency”, Journal of Finance, 48, 65-92

Jeegadesh N. and S. Titman, 1995, "Overreaction, delayed reaction and contrarian profits", The Review of Financial Studies, 8(4), 973-993.

Keim D. and A. Madhavan, 1995, "Anatomy of the trading process. Empirical evidence on the behavior of institutional traders," Journal of Financial Economics 37(3) p. 371-398.

Kim O. and R. Verrecchia, 1991, "Trading volume and price reactions to public announcements", Journal of accounting research, 29, 302-321.

Kraus A. and M. Smith, 1989, "Market created risk”, The Journal of Finance, 44, 557-569.

Lakonishok J. and E. Maberly (1990), “The Weekend Effect: Trading Patterns of Individual and Institutional Investors", Journal-of-Finance; 45(1), 231-43 
Lakonishok J. and A. Shleifer, 1992, "The Impact of Institutional Trading on Stock Prices", Journal of Financial Economics, 32(1), 23-43.

Lakonishok J., 1991, "Window Dressing by Pension Fund Managers", American Economic Review, 81(2), 227-31.

Lakonishok J., Shleifer A. and R. W. Vishny, 1993, "Contrarian Investment, Extrapolation, and Risk" University of Chicago Center for the Study of the Economy and the State Working Paper: 84.

Lakonishok J., A. Shleifer and R. W. Vishny, 1991, "Do Institutional Investors Destabilize Stock Prices? Evidence on Herding and Feedback Trading”, NBER Working Paper: 3846.

Lewellen W.G., Lease R.C. and G.C. Schlarbaum, 1979, "Investment performance and investor behavior", Journal of Financial and Quantitative Analysis", 14(1), 29-57.

Levy R. L., 1967, "Relative Strength as a Criterion for Investment Selection," Journal of Finance, Vol. 22, No. 4. (Dec.), pp. 595-610.

Lo A.W. and A.C. MacKinlay, 1990, "When are Contrarian Profits Due to Stock Market Overreaction?" Review of Financial Studies, Vol. 3, No. 2. , pp. 175-205.

Lynch A. W. and R.R Mendenhall, 1997, "New evidence on stock price effects associated with changes in the S\&P500 index", Journal of Business 70: (3) 351-383.

Knez P. J. and M. J. Ready, 1996, “Estimating the profits from trading strategies”, the Review of Financial Studies, 9(4), 1121-1163

Miller M. H., Muthuswamy J, and R.E. Whaley, 1994, “Mean reversion of Standard and Poor's 500 Index Basis Changes: Arbitrage Induced or Statistical Illusion?”, Journal of Finance 49: (2) 479-513.

Musto D. K., 1997 "Portfolio Disclosures and Year-End Price Shifts", Journal-of-Finance; 52(4), 1563-88.

Odean T. 1998 “Are Investors Reluctant to Realize Their Losses?”, Journal-of-Finance; 53(5), 17751798.

Orosel G., 1998, "Participation costs, Trend-Chasing, and Volatiilty of Stock Prices," The Review of Financial Studies 11(3), p. 521-558.

Rosenberg B., K. Reid and R. Lanstein, 1984, "Persuasive Evidence of Market Inefficiency," Jounral of Portfolio Management, 11(3) 9-17. 
Shalen C. T., 1993, "Volume, volatility and the dispersion of beliefs", The review of Financial Studies, 6, 405-434.

Sharpe W. 1992, "Asset allocation,: Management Style and Performance Measurement," Journal of Portfolio Management, 7-19.

Shiller R, 1998 “ Comment on Vincent Warther, "Has the Rise of Mutual Funds Increased Market Instability?" " Brooking-Wharton Papers

Shleifer A., July 1986, Do Demand Curves for Stocks Slope Down?, Journal of Finance, 41(3), 579-590.

Sias R.W. and L.T. Starks, (1996) "Return Autocorrelation and Institutional Investors", Journal of Financial Economics, 46, 103-31.

Sirri E. R. and P. Tufano (1993), "Buying and selling mutual funds: flows, performance, fees and service", Working Paper, Harvard Business School.

Stulz R. M., 1997, “Do foreign investors destabilize stock markets? The Korean experience in 1997”, Mimeo, Charles A. Dice Center for Research in Financial Economics.

Stulz R. M., 1999, "International portfolio flows and security markets", Mimeo, The Ohio State University.

Whaley R. E. and D. Messod, 1996, "An Anatomy of the "S\&P Game": The Effects of Changing the Rules”, Journal of Finance; 51(5), 1909-30.

Williams J., 1977, " Capital asset prices with heterogeneous beliefs", Journal of Financial Economics, 219-277.

Zheng, L. 1997, "Stock Prices and Investment Cash Flows," Yale School of Management Working Paper, 1997.

Zheng, L. 1998, "Who Moves the Market," Working paper, University of Michigan Business School. 


\section{Table 1: Descriptive Statistics}

Investors are grouped into 4 categories, on the basis of some institutional differences. The Individuals Accounts include: Administrator, Individual, Non-Prototype Individual, Sole Proprietorship, and Personal Representative. The Tax-benefited Accounts include Traditional IRA, UTMA, Rollover IRA, Sep-IRA, Joint-WROs, Money Purchase Keogh, Non-Prototype IRA, ROTH IRA, Simple IRA and PS Voluntary Keogh. The Fiduciary and Trusts Accounts include the Conservator, Executor, Fiduciary, Guardian, Transfer on Death-Individual, Trust: under Agreement, Trust under Indenture, Trust under Will. The Groups Accounts include the Bank, Religious Organisation, Joint CP, Corporation, Investment Club, Professional Corp., Partnership, Joint TIC, Joint TBE, Unincorporated Association, UGMA, Professional Association. Running Balance is constructed as the average holdings standardised by the amount of time they are held. Turnover is calculated as the absolute sum of purchases and sales (expressed in terms of number of shares) in the fund divided by the average running balance. Investor Profit Ratio is calculated as the ratio between the terminal value of the sum of the inflows and outflows each accrued at the return on the index fund and the terminal value of a buy and hold strategy.

Number of Accounts

Number of Transactions

Percentage of Purchases

Percentage of Sales

Running Balance

(in number of shares)

Turnover Ratio

Investor Profit Ratio

Median
S. dev

Number of Transactions

Mean

Median

S. dev

\begin{tabular}{rrrrr} 
Individuals & \multicolumn{1}{c}{ Tax-benefited } \\
Accounts & \multicolumn{1}{c}{$\begin{array}{c}\text { Fiduciary } \\
\text { and Trust }\end{array}$} & Groups & \multicolumn{1}{c}{ Total } \\
\hline 16,185 & 66,903 & 5,493 & 2,179 & 90,768 \\
51,864 & 185,059 & 15,558 & 7,119 & 259,614 \\
0.82 & 0.82 & 0.83 & 0.81 & 0.82 \\
0.18 & 0.17 & 0.16 & 0.18 & 0.17 \\
& & & & \\
400 & 254 & 584 & 1341 & 327 \\
170 & 116 & 244 & 195 & 134 \\
1,106 & 665 & 2,061 & 2,259 & 3,617 \\
& & & & \\
30.18 & 16.55 & 202.35 & 15.68 & 30.23 \\
1.12 & 1.02 & 1.03 & 1.11 & 1.03 \\
997.19 & 608.69 & $12,556.5$ & 1,250 & 3,160 \\
& & & & \\
1.17 & 1.19 & 1.97 & 1.21 & 1.23 \\
0.85 & 0.88 & 0.85 & 0.84 & 0.87 \\
6.14 & 13.14 & 68.41 & 5.05 & 20.44 \\
& & & & \\
3.20 & 2.76 & 2.83 & 3.26 & 2.86 \\
2.00 & 2.00 & 2.00 & 2.00 & 2.00 \\
4.30 & 3.82 & 4.79 & 5.09 & 4.01
\end{tabular}


Table 2: Typology of Contrarians and Momentum Investors

Return contrarians are defined as the investors who invest in the fund when the daily return of the index of the previous day is negative and return momentum are defined as the investors who invest in the fund when the daily return of the index of the previous day is positive. Volatility contrarians are defined as the investors who invest in the fund when the volatility of the day before the investment is increasing with respect to the previous day. Volatility is the implied volatility on the option on the SP500 as defined using the Black-Sholes pricing formula. Contrarians and momentum are defined as the agents who systematically play a strategy. A small sample test of equality between the distribution of investors' behavior and market returns based on the binomial distribution is applied and the investors with a statistic greater than $10 \%$ have been identified as contrarians or momentum investors. All the cases where the test is equal to zero or is not defined are called "undefined". Only accounts with at least 3 transactions are considered.

\section{All Accounts}

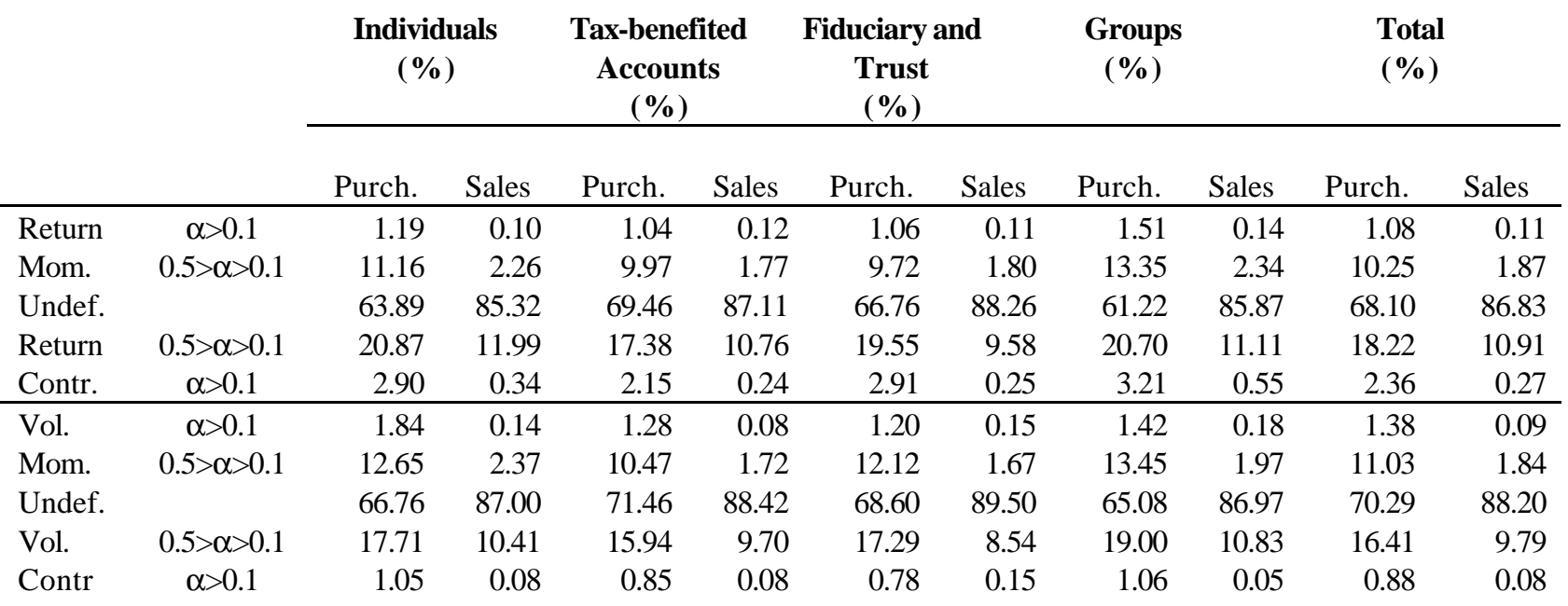

Accounts with more than 8 transactions

\begin{tabular}{|c|c|c|c|c|c|c|c|c|c|c|c|}
\hline & & Purch. & Sales & Purch. & Sales & Purch. & Sales & Purch. & Sales & Purch. & Sales \\
\hline Return & $\alpha>0.1$ & 10.40 & 0.89 & 12.38 & 1.26 & 11.07 & 2.29 & 17.16 & 1.49 & 11.99 & 1.24 \\
\hline Mom. & $0.5>\alpha>0.1$ & 35.38 & 9.33 & 38.92 & 7.96 & 40.46 & 9.92 & 39.55 & 10.45 & 38.21 & 8.44 \\
\hline Undef. & & 11.11 & 74.40 & 11.94 & 73.51 & 12.98 & 74.81 & 7.46 & 73.13 & 11.68 & 73.77 \\
\hline Return & $0.5>\alpha>0.1$ & 27.11 & 13.78 & 23.85 & 15.28 & 21.37 & 11.07 & 21.64 & 11.19 & 24.40 & 14.60 \\
\hline Contr. & $\alpha>0.1$ & 16.00 & 1.60 & 12.91 & 1.99 & 14.12 & 1.91 & 14.18 & 3.73 & 13.71 & 1.94 \\
\hline Vol. & $\alpha>0.1$ & 16.44 & 1.42 & 14.93 & 0.88 & 14.89 & 1.91 & 12.69 & 2.99 & 15.21 & 1.11 \\
\hline Mom. & $0.5>\alpha>0.1$ & 28.98 & 8.62 & 30.55 & 8.87 & 30.15 & 8.02 & 29.10 & 8.21 & 30.13 & 8.75 \\
\hline Undef. & & 15.56 & 76.62 & 12.91 & 75.83 & 15.65 & 77.48 & 11.19 & 79.10 & 13.61 & 76.18 \\
\hline Vol. & $0.5>\alpha>0.1$ & 28.62 & 12.36 & 30.49 & 13.37 & 29.77 & 9.54 & 37.31 & 8.96 & 30.21 & 12.82 \\
\hline Contr. & $\alpha>0.1$ & 10.40 & 0.98 & 11.12 & 1.05 & 9.54 & 3.05 & 9.70 & 0.75 & 10.83 & 1.13 \\
\hline
\end{tabular}


Table 3: Profitability of Contrarians and Momentum Traders

Profits are calculated as the terminal value of the sum of the inflows and outflows each accrued at the return on the index fund divided by the terminal value of a buy and hold strategy, assuming the investor had all investable funds at the beginning of the sample period. Profits are estimated for all the different classes of rational ivvestors as defined in Table 3 (purchase and sale contrarian and momentum investors). We also define an additional class of investor "full momentum" or "full contrarian," i.e. investors who have greater than $50 \%$ probability of being both purchase and sale momentum investors and analogously, those who have greater than $50 \%$ probability of being both purchase and sale contrarians. For each class the mean, median, standard deviation and the class size are reported. The tests on the differences of the means are tests based on the differences of means of normal distributions, with unknown variance. The tests on the differences of the medians are based on a pairwise comparison of the medians of the profitability of the alternative strategies implemented by using a Mann-Whitney Test. The test is based on the statistics: $U=\operatorname{Min}\left\{T_{1}, T_{2}\right\}$ where: $T_{1}=n_{1} * n_{2}+\frac{n_{1} *\left(n_{1}+1\right)}{2}-R_{1}$ and $T_{2}=n_{1} * n_{2}-T_{1}$. Here $n_{1}$ and $n_{2}$ are the size of the two samples which are compared and $R_{1}$ is the sum of the ranks for the sample corresponding to $n_{1}$. The ranks are calculated on the pooled samples. We report the values of the statistics z defined as: $z=\frac{U-\mu_{u}}{\sigma_{u}}$, where, by applying the normal approximation, $\mu_{u}=\frac{n_{1} * n_{2}}{2}$ and $\sigma_{u}=\sqrt{\frac{n_{1} * n_{2} *\left(n_{1}+n_{2}+1\right)}{12}}$. Both tests are two-sided. For both tests the probability values are reported.

\section{Return-Conditioned Strategies}

\begin{tabular}{|c|c|c|c|c|c|c|c|c|c|c|}
\hline & \multicolumn{4}{|c|}{ Contrarian Investors } & \multicolumn{4}{|c|}{ Momentum Investors } & \multicolumn{2}{|c|}{$\begin{array}{c}\text { Test of Difference } \\
\text { (P-values) }\end{array}$} \\
\hline & Mean & Median & Std & $\mathrm{N}$ & Mean & Median & Std & $\mathrm{N}$ & Mean & Median \\
\hline Purchases & 1.92 & 0.86 & 40.83 & 16,410 & 1.12 & 0.80 & 1.53 & 976 & 0.01 & 0.0001 \\
\hline Sales & 1.19 & 1.03 & 11.20 & 9,782 & 2.03 & 0.87 & 3.13 & 103 & 0.01 & 0.21 \\
\hline Full & 1.59 & 1.13 & 8.97 & 3,137 & 0.63 & 0.34 & 2.37 & 6 & 0.32 & 0.13 \\
\hline \multicolumn{11}{|c|}{ Volatility-Conditioned Strategies } \\
\hline & \multicolumn{4}{|c|}{ Contrarian Investors } & \multicolumn{4}{|c|}{ Momentum Investors } & \multicolumn{2}{|c|}{$\begin{array}{c}\text { Test of Difference } \\
\text { (P-values) }\end{array}$} \\
\hline & Mean & Median & Std & $\mathrm{N}$ & Mean & Median & Std & $\mathrm{N}$ & Mean & Median \\
\hline Purchases & 1.32 & 0.88 & 10.49 & 11,887 & 1.81 & 0.86 & 44.99 & 17,273 & 0.17 & 0.004 \\
\hline Sales & 2.54 & 1.19 & 52.13 & 9,974 & 2.22 & 1.82 & 30.73 & 8,288 & 0.60 & 0.0001 \\
\hline Full & 1.20 & 1.41 & 15.15 & 2,518 & 1.82 & 2.21 & 48.00 & 3,137 & 0.49 & 0.0001 \\
\hline
\end{tabular}


Table 4: Causality among investors:

Contrarians vs. momentum investors

The causality tests are Granger tests applied to the following VAR specification: Flows $_{t}=\alpha+\gamma$ Flows $_{t-1}+\varepsilon_{t}$, where Flows $_{\mathrm{t}}$ is the vector of investors' flows in and out the index fund (purchases and sales). The flows are defined in terms of number of shares purchased/sold and are aggregated into different groups depending on the characteristics of the investors. Investors are divided into momentum and contrarians. The momentum investors are defined as the investors who buy shares in the fund when the value of the fund is increasing (return momentum investors) or when the volatility of returns is increasing (volatility momentum investors). The contrarian investors are defined as the investors who buy shares in the fund when the value of the fund is decreasing (return contrarian investors) or when the volatility of returns is decreasing (volatility contrarian investors). Both contrarians and momentum are defined in terms of the reaction to the previous day returns/change in volatility. Volatility is the implied volatility on the option on the SP500 as defined using the Black-Sholes pricing formula. Contrarians and momentum are defined as the agents who systematically play a strategy. A small sample test of equality between the distribution of investors' behavior and market returns based on the binomial distribution is applied and the investors with a statistic greater than $10 \%$ have been identified as contrarians or momentum investors. The class Rest of the Market is defined as the residual investors who do not fall in the other two classes (i.e. are not either contrarians or momentum investors). The observations are daily for the period 1/1/1997-31/12/1998. The table contains the Probability values of the joint significance of the lagged values of the variables whose ability to Granger-cause the dependent varaible is to be tested. This value is bounded between 0 and 1 . It is 1 when the exogenous variables does not cause the endogenous one, while it is 0 when the exogenous variable causes the endogenous one. The VAR is estimated with 2 and 5 lags. The values for the 2 lags are reported within brackets.

Exogenous variables

Purchases

\section{Return Contrarians Rest of the Investors Return Momentum}

Return Contrarians Rest of the Investors Return Momentum
VolatilityContrarians
Rest of the Investors
Volatility.Momentum

VolatilityContrarians
Rest of the Investors
Volatility.Momentum

VolatilityContrarians
Rest of the Investors
Volatility.Momentum

VolatilityContrarians
Rest of the Investors
Volatility.Momentum

Endogenous Variables

\begin{tabular}{cccccc}
\multicolumn{2}{c}{ Return Contrarians } & \multicolumn{2}{c}{ Rest of the Investors } & \multicolumn{2}{c}{ Return Momentum } \\
\hline 2 Lags & 5 Lags & 2 Lags & 5 Lags & 2 Lags & 5 Lags \\
0.9971 & 0.9997 & 0.6972 & 0.8719 & 0.8843 & 0.9855 \\
0.7203 & 0.5660 & 0.0001 & 0.0001 & 0.3197 & 0.4522 \\
0.6682 & 0.7246 & 0.2702 & 0.1443 & 0.0114 & 0.0410 \\
\multicolumn{2}{c}{ Sales } & & & \\
2 Lags & 5 Lags & 2 Lags & 5 Lags & 2 Lags & 5 Lags \\
0.0001 & 0.0001 & 0.0001 & 0.0001 & 0.0001 & 0.0001 \\
0.0001 & 0.0001 & 0.3448 & 0.0012 & 0.0088 & 0.1134 \\
0.0001 & 0.0269 & 0.0012 & 0.0001 & 0.0317 & 0.0073
\end{tabular}

Purchases

\begin{tabular}{|c|c|c|c|c|c|}
\hline \multicolumn{2}{|c|}{ VolatilityContrarians } & \multicolumn{2}{|c|}{ Rest of the Investors } & \multicolumn{2}{|c|}{ Volatility.Momentum } \\
\hline 2 Lags & 5 Lags & 2 Lags & 5 Lags & 2 Lags & 5 Lags \\
\hline 0.0001 & 0.0001 & 0.8659 & 0.8902 & 0.7739 & 0.6348 \\
\hline 0.9993 & 0.6735 & 0.0001 & 0.0001 & 0.3736 & 0.8231 \\
\hline 0.0001 & 0.0003 & 0.0015 & 0.0052 & 0.9569 & 0.9548 \\
\hline \multicolumn{6}{|c|}{ Sales } \\
\hline 2 Lags & 5 Lags & 2 Lags & 5 Lags & 2 Lags & 5 Lags \\
\hline 0.0001 & 0.0001 & 0.0057 & 0.0001 & 0.0001 & 0.0001 \\
\hline 0.0003 & 0.0001 & 0.0001 & 0.0001 & 0.5228 & 0.6706 \\
\hline 0.0001 & 0.0001 & 0.0034 & 0.0077 & 0.0001 & 0.0005 \\
\hline
\end{tabular}


Table 5: Regressions of S\&P500 Returns on Flows of Contrarians and Momentum Investors

The functional specification estimated is $R_{t}=\alpha+\beta$ Flows $t+\varepsilon$, where $R_{t}$ is the return on the SP500 index, while Flows $s_{t}$ are the flows represent the purchases (inflows) and sales (outflows) of fund units by specified categories of investors (momentum and contrarians). Investors are divided into momentum and contrarians. The momentum investors are defined as the investors who buy shares in the fund when the value of the fund is increasing (return momentum investors) or when the volatility of returns is increasing (volatility momentum investors). The contrarian investors are defined as the investors who buy shares in the fund when the value of the fund is decreasing (return contrarian investors) or when the volatility of returns is decreasing (volatility contrarian investors). Both contrarians and momentum are defined in terms of the reaction to the previous day returns/change in volatility. Volatility is the implied volatility on the option on the SP500 as defined using the Black-Sholes pricing formula. Contrarians and momentum are the agents who systematically enact a strategy. A small sample test of equality between the distribution of investors' behavior and market returns based on the binomial distribution is applied and the investors with a statistic greater than $10 \%$ have been identified as contrarians or momentum investors. The estimation uses a consistent variance-covariance matrix based on the Newey-West correction. The value of the coefficient and the t-statistic are reported. Two samples are used: the whole period (01/01/1997-31/12/1998) and the subperiod 01/01/1998-31/12/1998. In the latter case, contrarians and momentum investors are identified in the first period (01/01/1997$31 / 12 / 1997)$ and then the estimations are based on portfolios made of their flows during the second period (01/01/1998-31/12/1998). The flows are divided by 10,000,000.

Full Sample (01/01/1997-31/12/1998)

Strategies defined on returms

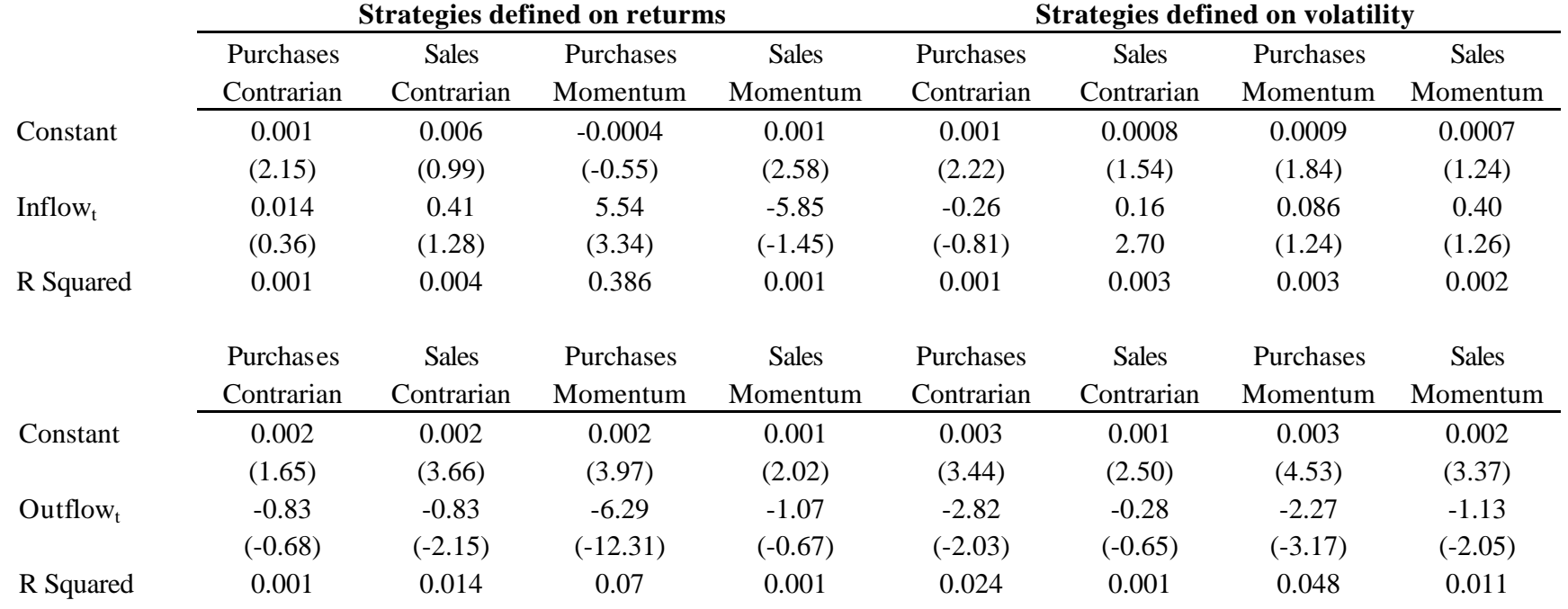

Out-of-sample (01/01/1998-31/12/1998) Strategies defined on returms

Strategies defined on volatility

\begin{tabular}{cccccccc}
\hline $\begin{array}{c}\text { Purchases } \\
\text { Contrarian }\end{array}$ & $\begin{array}{c}\text { Sales } \\
\text { Contrarian }\end{array}$ & $\begin{array}{c}\text { Purchases } \\
\text { Momentum }\end{array}$ & $\begin{array}{c}\text { Sales } \\
\text { Momentum }\end{array}$ & $\begin{array}{c}\text { Purchases } \\
\text { Contrarian }\end{array}$ & $\begin{array}{c}\text { Sales } \\
\text { Contrarian }\end{array}$ & $\begin{array}{c}\text { Purchases } \\
\text { Momentum }\end{array}$ & $\begin{array}{c}\text { Sales } \\
\text { Momentum }\end{array}$ \\
\hline 0.001 & 0.003 & 0.0005 & 0.001 & 0.001 & 0.004 & 0.001 & 0.001 \\
$(2.15)$ & $(0.55)$ & $(0.95)$ & $(2.08)$ & $(1.88)$ & $(0.83)$ & $(2.29)$ & $(2.38)$ \\
0.046 & 7.72 & 18.31 & 25.04 & -0.21 & 5.63 & -3.75 & -216.94 \\
$(0.40)$ & $(3.02)$ & $(2.51)$ & $(0.60)$ & $(-0.55)$ & $(2.63)$ & $(-0.27)$ & $(1.96)$ \\
0.001 & 0.015 & 0.013 & 0.001 & 0.001 & 0.017 & 0.001 & 0.004 \\
& & & & & & & Sales \\
Purchases & Sales & Purchases & Sales & Purchases & Sales & Purchases & Momentum \\
Contrarian & Contrarian & Momentum & Momentum & Contrarian & Contrarian & Momentum & Momen \\
\hline 0.001 & 0.001 & 0.002 & 0.001 & 0.003 & 0.001 & 0.003 & 0.002 \\
$(2.31)$ & $(3.85)$ & $(3.48)$ & $(2.67)$ & $(3.44)$ & $(2.50)$ & $(4.53)$ & $(3.37)$ \\
-1.47 & -6.01 & -25.80 & -65.33 & -0.0001 & -0.0001 & -0.0001 & -0.0001 \\
$(-0.89)$ & $(-2.71)$ & $(-2.33)$ & $(-1.39)$ & $(-2.29)$ & $(-0.65)$ & $(-3.17)$ & $(-2.05)$ \\
0.005 & 0.029 & 0.026 & 0.009 & 0.024 & 0.001 & 0.048 & 0.013
\end{tabular}




\section{Table 6: Time-Varying Sharpe Coefficients}

Portfolios are constructed by minimizing the squared residual error of the vector of returns of the S\&P500 index by using investors' purchases and sales as explanatory variables, subject to the constraint that the weights in the portfolios are positive and add up to one. In particular, we estimate: $\operatorname{Min}_{w_{t}}\left[R_{t}-\mathrm{w}_{\mathrm{t}} \mathrm{Flow}_{t}\right]^{2}$ s.t.: $\mathrm{w}_{\mathrm{t}} * \mathrm{e}=1$ and $w_{i t} \geq 0 \forall i$. Here $\mathrm{w}_{\mathrm{t}}$ is a vector of weights of size equal to the number of components of the portfolio of flows, Flow $t_{t}$ is vector of length $\mathrm{i}$ comprised of flows for day $\mathrm{t}$ for class purchase or sale $\mathrm{i}$ (purchases or sales of shares by contrarians on day $\mathrm{t}$, purchases or sales by the rest of the market, or purchases or sales by momentum investors) and $\mathbf{e}$ is a vector of ones. The weights $\left(\mathrm{W}_{\mathrm{t}}\right)$ are reported for the different specifications. Three specifications are estimated: in the first one we assume that only net purchases (purchases minus sales) affect returns. We therefore consider the net flows of the 4 classes of strategic investors (return contrarian, return momentum, volatility contrarian and volatility momentum). In the second specifications we consider separately purchases and sales for the 4 classes of strategic investors. The assumption is that purchases and sales make up the whole portfolio separately. In the third specification we consider the breakdown in purchases and sales for the 4 classes of strategic investors under the assumption that purchases and sales jointly make up the whole portfolio. For all the three specifications the values reported in each row add up one. Investors are divided into momentum and contrarians. The momentum investors are defined as the investors who buy shares in the fund when the value of the fund is increasing (return momentum investors) or when the volatility of returns is increasing (volatility momentum investors). The contrarian investors are defined as the investors who buy shares in the fund when the value of the fund is decreasing (return contrarian investors) or when the volatility of returns is decreasing (volatility contrarian investors). Both contrarians and momentum are defined in terms of the reaction to the previous day returns/change in volatility. The different classes of investors have been identified in the period 01/01/1997-31/12/1997 and then the portfolios have been constructed "out-of-sample" for the period 01/01/1998-31/12/1998.

\section{Specification}

Return Contr.Net Purch. $\quad$ Return.Mom.Net Purch. $\quad$ Volat.Contr.Net Purch. $\quad$ Volat.Mom.Net Purch.
0.00
0.381
0.00
0.618

II Specification

Return Contr.Purch.

0.118

0.247

Volat.Mom.Purch.

Volat.Contr.Purch.
Return.Contr.Sales

0.634

0.00
Volat.Contr.Sales

0.119

III Specification

\begin{tabular}{cccccccc}
$\begin{array}{c}\text { Return } \\
\text { Contr.Purch }\end{array}$ & $\begin{array}{c}\text { Return. } \\
\text { Mom.Purch }\end{array}$ & $\begin{array}{c}\text { Return. } \\
\text { Contr.Sales }\end{array}$ & $\begin{array}{c}\text { Return } \\
\text { Mom.Sales }\end{array}$ & $\begin{array}{c}\text { Volat. } \\
\text { Contr.Purch }\end{array}$ & $\begin{array}{c}\text { Volat. } \\
\text { Mom.Purch }\end{array}$ & $\begin{array}{c}\text { Volat. } \\
\text { Contr.Sales }\end{array}$ & $\begin{array}{c}\text { Volat } \\
\text { Mom.Sales }\end{array}$ \\
\hline 0.069 & 0.058 & 0.0337 & 0.00 & 0.355 & 0.152 & 0.00 & 0.027
\end{tabular}


Table 7: Stock returns and behavioral factors

The table reports the means of the $\mathrm{R}^{2}$ from the daily cross-sectional of the second stage of a Fama-MacBeth procedure with either 4 or 8 factors: four extracted from past returns and four based on the investors' flows orthogonalized by regressing them on the first four factors. The table also reports the P-values of the test that the means of the $\mathrm{R}^{2}$ of the regressions based on behavioral factors are statistically different from the means of the $\mathrm{R}^{2}$ estimated using only past market factors. The factor loadings are estimated for a set of portfolios formed from both stock returns and investors' flows using a four-factor latent variable model. In the former case, we consider the regularly-traded individual securities in the U.S. market. The factors are extracted and loadings estimated using leading rolling windows. For the returns, we take the 560 stocks in the CRSP database that have been consecutively traded in the two-year period 1997-1998 with no missing observations. We then create 20 portfolios each containing 28 stocks, ranked by market capitalization. For the flows, we consider the daily flows into the fund (purchases and sales) of various combinations of investors, aggregated in terms of their trading behavior. This is defined in terms of the class of investors we identified before: momentum and contrarian investors. Strategies are broken down in terms of their definition as reaction to returns and volatility (contrarian and momentum). We consider three specifications. In the first one there are only the four factors which have been extracted from previous stock returns. In the second specification, we use "portfolios of flows". These are based on the flows of the return contrarians, return momentum investors, volatility contrarians and volatility momentum investors. Each single portfolio is composed of both the purchases and sales of the investors belonging to the specific category, one factor for each way of identifying them. For example, the portfolio of return contrarians is made of four components: the vector of the purchases of the contrarian investors identified as contrarians on the basis of their sales, the vector of the purchases of the contrarian investors identified as contrarians on the basis of their purchases, the vector of the sales of the contrarian investors identified as contrarians on the basis of their sales and the vector of the purchases of the contrarian investors identified as contrarians on the basis of their purchases. In the third specification, we consider portfolios made by purchases and sales separately considered. We therefore have purchases of return investors, purchases of volatility investors, sales of return investors, sales of volatility investors, net purchases (purchases minus sales) of return investors and net purchases of volatility investors. For example the portfolio of the purchases of return investors is made of four factors: the purchases of the return contrarians identified as contrarians on the basis of their purchases, the purchases of the return contrarians identified as contrarians on the basis of their sales, the purchases of the return momentum investors identified as momentum investors on the basis of their purchases, the purchases of the return momentum investors identified as momentum investors on the basis of their sales. Loadings for each portfolio and portfolio weights are estimated via a principal component analysis performed on over-lapping 90 days windows through the sample period. A Dimson-Marsh correction using two days of leads and lags is applied to control for potential lead-lag effects due to asynchronous trading. The factor extraction and the estimation of the betas are updated each day in the sample, following the initial 90-day estimation period. Thus, betas are allowed to vary through time. In stage 2 , we regress portfolio returns on betas for each day following the estimation period. For the second and the third specification there are two different sets of estimations: one based only on the four factors derived from portfolio flows and one estimated with eight factors: the four based on portfolio flows and the four based on the factors derived using only past stock returns.

\begin{tabular}{lcccc}
\multicolumn{2}{c}{ 4 Factors } & \multicolumn{2}{c}{ 8 Factors } \\
\hline & Mean & $\begin{array}{c}\text { P } \\
\text { I Specification }\end{array}$ & Mean \\
Ret & 0.090 & - & 0.090 & - \\
& & & \\
Ret Contr. & 0.114 & II Specification & 0.1662 & 0.00001 \\
Ret Mom. & 0.087 & 0.22 & 0.1496 & 0.00001 \\
Volat.Contr & 0.131 & 0.06 & 0.2006 & 0.00001 \\
Volat.Mom & 0.108 & 0.63 & 0.1597 & 0.00001 \\
& & & \\
Ret Inv. Purchases & 0.103 & III Specification & 0.1387 & 0.004 \\
Volat.Inv. Purchases & 0.142 & 0.52 & 0.1659 & 0.00001 \\
Ret.Inv. Sales & 0.092 & 0.01 & 0.1949 & 0.00001 \\
Volat Inv. Sales & 0.105 & 0.46 & 0.1825 & 0.00001 \\
Ret. Inv. Net.Purch. & 0.078 & 0.56 & 0.1324 & 0.02 \\
Volat. Inv. Purchases & 0.087 & 0.90 & 0.1582 & 0.0001
\end{tabular}


Table 8: Stock returns and dispersion of beliefs

The table reports the means of the $\mathrm{R}^{2}$ from the daily cross-sectional of the second stage of a Fama-MacBeth procedure with 12 factors: four extracted from past returns, four based on the investors' flows orthogonalized by regressing them on the first four factors (behavioral factors) and four factors based on the dispersion of beliefs. The table also reports the P-values of the tests wheteher the means of the $\mathrm{R}^{2}$ of the regressions without the factors based on dispersion of beliefs are statistically different from the means of the $\mathrm{R}^{2}$ estimated using only the factors based on past returns and behavioral factors. Dispersion of beliefs generate four factors, constructed as the absolute differences between purchases of contrarian and moementum investors, both defined in terms of return and volatility (Return based Polarization of purchases and Volatility based Polarization of purchases), as well as the absolute differences between sales of contrarian and moementum investors, both defined in terms of return and volatility (Return based Polarization of sales and Volatility based Polarization of sales). The factor loadings are estimated for a set of portfolios formed from both stock returns and investors' flows using a four-factor latent variable model. In the former case, we consider the regularly-traded individual securities in the U.S. market. The factors are extracted and loadings estimated using leading rolling windows. For the returns, we take the 560 stocks in the CRSP database that have been consecutively traded in the two-year period 1997-1998 with no missing observations. We then create 20 portfolios each containing 28 stocks, ranked by market capitalization. For the flows, we consider the daily flows into the fund (purchases and sales) of various combinations of investors, aggregated in terms of their trading behavior. This is defined in terms of the class of investors we identified before: momentum and contrarian investors. Strategies are broken down in terms of their definition as reaction to returns and volatility (contrarian and momentum). We consider two specifications. In the first one, the behavioral factors are based on the "portfolios of flows" of: return contrarians, return momentum investors, volatility contrarians and volatility momentum investors. Each single portfolio is composed of both the purchases and sales of the investors belonging to the specific category, one factor for each way of identifying them. For example, the portfolio of return contrarians is made of four components: the vector of the purchases of the contrarian investors identified as contrarians on the basis of their sales, the vector of the purchases of the contrarian investors identified as contrarians on the basis of their purchases, the vector of the sales of the contrarian investors identified as contrarians on the basis of their sales and the vector of the purchases of the contrarian investors identified as contrarians on the basis of their purchases. In the second specification, the four behavioral factors are made of purchases and sales separately considered. We therefore have purchases of return investors, purchases of volatility investors, sales of return investors, sales of volatility investors, net purchases (purchases minus sales) of return investors and net purchases of volatility investors. For example the portfolio of the purchases of return investors is made of four factors: the purchases of the return contrarians identified as contrarians on the basis of their purchases, the purchases of the return contrarians identified as contrarians on the basis of their sales, the purchases of the return momentum investors identified as momentum investors on the basis of their purchases, the purchases of the return momentum investors identified as momentum investors on the basis of their sales. Loadings for each portfolio and portfolio weights are estimated via a principal component analysis performed on over-lapping 90 days windows through the sample period. A Dimson-Marsh correction using two days of leads and lags is applied to control for potential lead-lag effects due to asynchronous trading. The factor extraction and the estimation of the betas are updated each day in the sample, following the initial 90-day estimation period. Thus, betas are allowed to vary through time. In stage 2 , we regress portfolio returns on betas for each day following the estimation period.

\begin{tabular}{llc} 
& Mean & P \\
Ret. Contr. & \multicolumn{1}{c}{ I Specification } \\
Ret .Mom. & 0.2459 & 0.004 \\
Volat. Contr & 0.2214 & 0.007 \\
Volat. Mom & 0.2169 & 0.53 \\
& 0.2489 & 0.001 \\
Ret Inv. Purchases & II Specification & \\
Volat. Inv. Purchases & 0.2133 & 0.01 \\
Ret. Inv. Sales & 0.2113 & 0.08 \\
Volat. Inv. Sales & 0.2225 & 0.40 \\
Ret. Inv. Net. Purch. & 0.2061 & 0.37 \\
Volat. Inv. Net. Purch. & 0.2289 & 0.003 \\
& 0.2094 & 0.04
\end{tabular}


Table 9: Stock returns and dispersion of beliefs

The functional specification estimated is $\operatorname{Res}_{t}=\alpha+\sum \beta_{k} D B_{k t}+\varepsilon_{t}$, where $\operatorname{Res}_{t}$ is the residual of the second stage of the Fama-MacBeth procedure computed using 8 factors: four extracted from past returns (standard market factors), four based on the investors' flows orthogonalized by regressing them on the first four factors (behavioral factors). $\mathrm{DB}_{\mathrm{kt}}$ are the dispersion of beliefs, calculated as the absolute differences between purchases of contrarian and moementum investors, both defined in terms of return and volatility (Return based Polarization of purchases and Volatility based Polarization of purchases), as well as the absolute differences between sales of contrarian and moementum investors, both defined in terms of return and volatility (Return based Polarization of sales and Volatility based Polarization of sales). Investors are divided into momentum and contrarians. The factor loadings are estimated for a set of portfolios formed from both stock returns and investors' flows using a four-factor latent variable model. In the former case, we consider the regularly-traded individual securities in the U.S. market. The factors are extracted and loadings estimated using leading rolling windows. For the returns, we take the 560 stocks in the CRSP database that have been consecutively traded in the two-year period 1997-1998 with no missing observations. We then create 20 portfolios each containing 28 stocks, ranked by market capitalization. In the case of flows, we extract the factors from transactions (either purchases, or sales or net purchases) of the investors who strategically react to either return or volatility. We consider 5 specifications which differ, depending on the composition of the factors used in the first two steps of the Fama-MacBeth procedure. In the first specification only factors based on past return are used, in the other four we use factors exctracted from different "portfolios of flows" of the investors. These are the flows of return contrarians, return momentum investors, volatility contrarians and volatility momentum investors. Each single portfolio is composed of both the purchases and sales of the investors belonging to the specific category, one factor for each way of identifying them. For example, the portfolio of return contrarians is made of four components: the vector of the purchases of the contrarian investors identified as contrarians on the basis of their sales, the vector of the purchases of the contrarian investors identified as contrarians on the basis of their purchases, the vector of the sales of the contrarian investors identified as contrarians on the basis of their sales and the vector of the purchases of the contrarian investors identified as contrarians on the basis of their purchases. Loadings for each portfolio and portfolio weights are estimated via a principal component analysis performed on over-lapping 90 days windows through the sample period. A Dimson-Marsh correction using two days of leads and lags is applied to control for potential lead-lag effects due to asynchronous trading. The factor extraction and the estimation of the betas are updated each day in the sample, following the initial 90-day estimation period. Thus, betas are allowed to vary through time In stage 2, we regress portfolio returns on betas for each day following the estimation period. The slope coefficients are multiplied by a factor of $10^{7}$.

\begin{tabular}{|c|c|c|c|c|c|c|c|c|c|c|}
\hline & \multicolumn{10}{|c|}{ Specifications } \\
\hline & \multicolumn{2}{|c|}{ Return } & \multicolumn{2}{|c|}{ Return Contr. } & \multicolumn{2}{|c|}{ Return Mom. } & \multicolumn{2}{|c|}{ Volat. Contr. } & \multicolumn{2}{|c|}{ Volat. Mom. } \\
\hline & Value & TSta & Value & Tsta & Value & TSta & Value & TSta & Value & TSta \\
\hline Constant & 0.002 & 25.98 & 0.002 & 16.13 & 0.002 & 22.08 & 0.002 & 22.01 & 0.002 & 17.51 \\
\hline Return based & & & & & & & & & & \\
\hline $\begin{array}{l}\text { Polarizat. of } \\
\text { purch. }\end{array}$ & -0.034 & -2.90 & -0.02 & -0.36 & -0.010 & -0.11 & -0.059 & -0.68 & -0.040 & -0.54 \\
\hline Return based & & & & & & & & & & \\
\hline $\begin{array}{l}\text { Polarizat.of } \\
\text { sales }\end{array}$ & 0.045 & 0.38 & 0.27 & 1.50 & 0.277 & 2.11 & 0.286 & 2.13 & 0.262 & 1.64 \\
\hline $\begin{array}{l}\text { Volatility } \\
\text { based Polarizat } \\
\text { of purch. }\end{array}$ & 0.229 & 2.12 & 0.37 & 3.05 & 0.347 & 3.19 & 0.384 & 3.80 & 0.307 & 2.32 \\
\hline $\begin{array}{l}\text { Volatility } \\
\text { based Polarizat } \\
\text { of sales }\end{array}$ & 0.121 & 1.27 & -0.19 & -1.02 & -0.063 & -0.65 & -0.080 & -1.06 & -0.016 & -0.13 \\
\hline R Square & \multicolumn{2}{|c|}{0.124} & \multicolumn{2}{|c|}{0.190} & \multicolumn{2}{|c|}{0.241} & \multicolumn{2}{|c|}{0.199} & \multicolumn{2}{|c|}{0.177} \\
\hline
\end{tabular}


Table 10: Stock returns and behavioral factors

The functional specification estimated is $\operatorname{Res}_{t}=\alpha+\sum \beta_{\mathrm{k}} \mathrm{DB}_{\mathrm{kt}}+\varepsilon_{\mathrm{t}}$, where $\operatorname{Res}_{t}$ is the residual of the second stage of the Fama-MacBeth procedure computed using 8 factors: four extracted from past returns (standard market factors), four based on the investors' flows orthogonalized by regressing them on the first four factors (behavioral factors). $\mathrm{DB}_{\mathrm{kt}}$ are the dispersion of beliefs, calculated as the absolute differences between purchases of contrarian and moementum investors, both defined in terms of return and volatility (Return based Polarization of purchases and Volatility based Polarization of purchases), as well as the absolute differences between sales of contrarian and moementum investors, both defined in terms of return and volatility (Return based Polarization of sales and Volatility based Polarization of sales). Investors are divided into momentum and contrarians. The factor loadings are estimated for a set of portfolios formed from both stock returns and investors' flows using a four-factor latent variable model. In the former case, we consider the regularlytraded individual securities in the U.S. market. The factors are extracted and loadings estimated using leading rolling windows. For the returns, we take the 560 stocks in the CRSP database that have been consecutively traded in the twoyear period 1997-1998 with no missing observations. We then create 20 portfolios each containing 28 stocks, ranked by market capitalization. In the case of flows, we extract the factors from transactions (either purchases, or sales or net purchases) of the investors who strategically react to either return or volatility. We consider 4 specifications which differ, depending on the composition of the factors used in the first two steps of the Fama-MacBeth procedure. We consider portfolios made by purchases and sales separately considered. We therefore have purchases of return investors, purchases of volatility investors, sales of return investors, sales of volatility investors, net purchases (purchases minus sales) of return investors and net purchases of volatility investors. For exa mple the portfolio of the purchases of return investors is made of four factors: the purchases of the return contrarians identified as contrarians on the basis of their purchases, the purchases of the return contrarians identified as contrarians on the basis of their sales, the purchases of the return momentum investors identified as momentum investors on the basis of their purchases, the purchases of the return momentum investors identified as momentum investors on the basis of their sales.Loadings for each portfolio and portfolio weights are estimated via a principal component analysis performed on over-lapping 90 days windows through the sample period. A Dimson-Marsh correction using two days of leads and lags is applied to control for potential leadlag effects due to asynchronous trading. The factor extraction and the estimation of the betas are updated each day in the sample, following the initial 90-day estimation period. Thus, betas are allowed to vary through time In stage 2, we regress portfolio returns on betas for each day following the estimation period. The slope coefficients are multiplied by a factor of $10^{7}$.

\begin{tabular}{|c|c|c|c|c|c|c|c|c|c|c|c|c|}
\hline & \multicolumn{12}{|c|}{ Specifications } \\
\hline & \multicolumn{2}{|c|}{$\begin{array}{l}\text { Ret.Invest. } \\
\text { Purchases. }\end{array}$} & \multicolumn{2}{|c|}{$\begin{array}{l}\text { Volat.Invest. } \\
\text { Purchases }\end{array}$} & \multicolumn{2}{|c|}{$\begin{array}{l}\text { Ret.Invest. } \\
\text { Sales }\end{array}$} & \multicolumn{2}{|c|}{$\begin{array}{c}\text { Volat. Invest. } \\
\text { Sales }\end{array}$} & \multicolumn{2}{|c|}{$\begin{array}{l}\text { Ret.Invest. } \\
\text { Net } \\
\text { Purchases }\end{array}$} & \multicolumn{2}{|c|}{$\begin{array}{c}\text { Volat. Invest. } \\
\text { Net } \\
\text { Purchases }\end{array}$} \\
\hline & Value & TSta & Value & Tsta & Value & Tsta & Value & TSta & Value & TSta & Value & TSta \\
\hline $\begin{array}{l}\text { Constant } \\
\text { Return based }\end{array}$ & 0.002 & 24.48 & 0.002 & 23.97 & 0.002 & 20.32 & 0.002 & 20.20 & 0.002 & 22.17 & 0.002 & -0.04 \\
\hline $\begin{array}{l}\text { Polarizat. of } \\
\text { purch. } \\
\text { Return based }\end{array}$ & 0.005 & 0.06 & -0.056 & -0.72 & -0.048 & -0.54 & -0.034 & -0.40 & -0.03 & -0.45 & -0.115 & 0.23 \\
\hline $\begin{array}{l}\text { Polarizat.of } \\
\text { sales }\end{array}$ & 0.123 & 0.91 & 0.170 & 1.33 & 0.231 & 1.50 & 0.307 & 2.16 & 0.35 & 2.12 & 0.270 & 0.15 \\
\hline $\begin{array}{l}\text { Volatility } \\
\text { based Polarizat } \\
\text { of purch. }\end{array}$ & 0.216 & 2.48 & 0.311 & 3.41 & 0.154 & 1.34 & 0.367 & 3.83 & 0.32 & 2.95 & 0.224 & 0.08 \\
\hline $\begin{array}{l}\text { Volatility } \\
\text { based Polarizat } \\
\text { of sales }\end{array}$ & 0.028 & 0.37 & -0.079 & -0.97 & 0.088 & 0.89 & -0.043 & -0.50 & -0.06 & -0.66 & 0.049 & -0.04 \\
\hline R Square & & & & & & & & & & & & \\
\hline
\end{tabular}


Table 11: Market Impact of Contrarians and Momentum Investors Dispersion of beliefs and market returns: Market Polarization

The functional specification estimated is $r_{t}^{2}=\alpha+\gamma \mathrm{MPI}_{t}+\delta \mathrm{MPO}_{\mathrm{t}}+\varepsilon_{\mathrm{t}}$, where $\mathrm{R}_{\mathrm{t}}^{2}$ is the average corrected R square of the cross-section regression of the stock returns on the on the pre-estimated betas. $\mathrm{MPI}_{\mathrm{t}}$ and $\mathrm{MPO}_{\mathrm{t}}$ represent our measures of market polarization. In particular, MPI ${ }_{t}$ is the absolute difference between the purchases of the momentum and the purchases of the contrarian investors and $\mathrm{MPO}_{\mathrm{t}}$ is the absolute difference between the sales of the momentum and the sales of the contrarian investors. .Contrarians and momentum are the agents who systematically play a strategy. A small sample test of equality between the distribution of investors' behavior and market returns is applied. The statistic is distributed as a Binomial one. The betas have been constructed using a Fama-MacBeth methodology. In particular, we created 20 portfolios each containing 28 stocks, ranked according to market capitalization. This accounted, among the biggest stocks, for the 560 that have been consecutively traded in the 2 year period 1997-1998. This allows us to cover all the stocks contained in the S\&P500 who also have been consecutively traded. For each portfolio the betas have estimated regressing the average portfolio return on the four factors extracted using a principal component technique in the previous 90 days. In order to estimate the betas, a Dimson's correction is applied, by using 2 days of lags and 2 days of leads. The factor extraction and the estimation of the betas are carried out on overlapping windows every day. This generates 412 cross-sections of betas that are used as explanatory variables in the second step of the procedure, where portfolio returns are regressed on betas. The resulting times-series of $412 \mathrm{R}_{\mathrm{t}}^{2} \mathrm{~s}$ has been regressed on our measures of market polarization. The estimation has been carried out using instrumental GMM, with Newey-West correction on the variance-covariance matrix based on 5 lags autocorrelation structure. The choice of the instruments has been based on Hansen's over-identification criterion. The instruments are: time dummies, a constant, dividend yield and yield on corporate bonds have been used. The flows are divided by 10,000.

\begin{tabular}{|c|c|c|c|c|c|c|}
\hline & \multicolumn{2}{|c|}{ Total } & \multicolumn{2}{|c|}{ Purchases } & \multicolumn{2}{|c|}{ Sales } \\
\hline & Value & t-stat & Value & t-stat & Value & t-stat \\
\hline Constant & 1.01 & 1.64 & 0.12 & 4.39 & 0.13 & 8.62 \\
\hline $\begin{array}{l}\text { Mkt.Polariz.t } \\
\text { (Purchases) }\end{array}$ & 0.29 & 0.69 & 1.96 & 1.42 & - & - \\
\hline $\begin{array}{l}\text { Mkt.Polariz.t } \\
\text { (Sales) }\end{array}$ & -1.32 & -2.19 & - & - & -.135 & -2.12 \\
\hline $\begin{array}{l}\text { Chi-Squared } \\
\text { (p value) }\end{array}$ & \multicolumn{2}{|c|}{$\begin{array}{c}1.51 \\
(0.22)\end{array}$} & \multicolumn{2}{|c|}{$\begin{array}{c}1.26 \\
(0.27)\end{array}$} & \multicolumn{2}{|c|}{$\begin{array}{c}1.85 \\
(0.39)\end{array}$} \\
\hline
\end{tabular}


Figures 1-2

The following graphs report the weights of the portfolios constructed by minimizing the squared residual error of the vector of returns of the S\&P500 index by using investors' purchases and sales as explanatory variables, subject to the constraint that the weights in the portfolios are positive and add up to one. In particular, we estimate: $\operatorname{Min}_{w_{t}}\left[R_{t}-\mathrm{w}_{\mathrm{t}} \text { Flow }_{t}\right]^{2} \quad$ s..t.: $\mathrm{w}_{\mathrm{t}} * \mathrm{e}=1$ and $w_{i t} \geq 0 \forall i$. Here $\mathrm{w}_{\mathrm{t}}$ is a vector of weights of size equal to the number of components of the portfolio of flows, Flow ${ }_{t}$ is vector of length $\mathrm{i}$ comprised of flows for day $\mathrm{t}$ for class purchase or sale i (purchases or sales of shares by contrarians on day t, purchases or sales by the rest of the market, or purchases or sales by momentum investors) and $\mathbf{e}$ is a vector of ones. The weights have been identified through a rolling regression procedure with a 90 days estimation window. The contrarians and the momentum investors have been identified in the first period (01/01/1997-31/12/1997) and then their behavior has been tracked in the second period (01/01/1998-31/12/1998). Two different specifications are reported. In the first one we assume that only net purchases (purchases minus sales) affect returns (Figure 1). We therefore consider the net flows of the 4 classes of strategic investors (return contrarian, return momentum, volatility contrarian and volatility momentum). In the third specification we consider the breakdown in purchases and sales for the 4 classes of strategic investors under the assumption that purchases and sales jointly make up the whole portfolio. (Figure 2). In each Figure the weights $\left(\mathrm{W}_{\mathrm{t}}\right)$ are represented by the size of the area. Five days moving averages are used. For both specifications the percentage values of all the weights add up to one. Investors are divided into momentum and contrarians. The momentum investors are defined as the investors who buy shares in the fund when the value of the fund is increasing (return momentum investors) or when the volatility of returns is increasing (volatility momentum investors). The contrarian investors are defined as the investors who buy shares in the fund when the value of the fund is decreasing (return contrarian investors) or when the volatility of returns is decreasing (volatility contrarian investors). Both contrarians and momentum are defined in terms of the reaction to the previous day returns/change in volatility. The different classes of investors have been identified in the period 01/01/1997-31/12/1997 and then the portfolios have been constructed "out-ofsample" for the period 01/01/1998-31/12/1998. 
Figure 1

Percentage impact of different strategies on market return

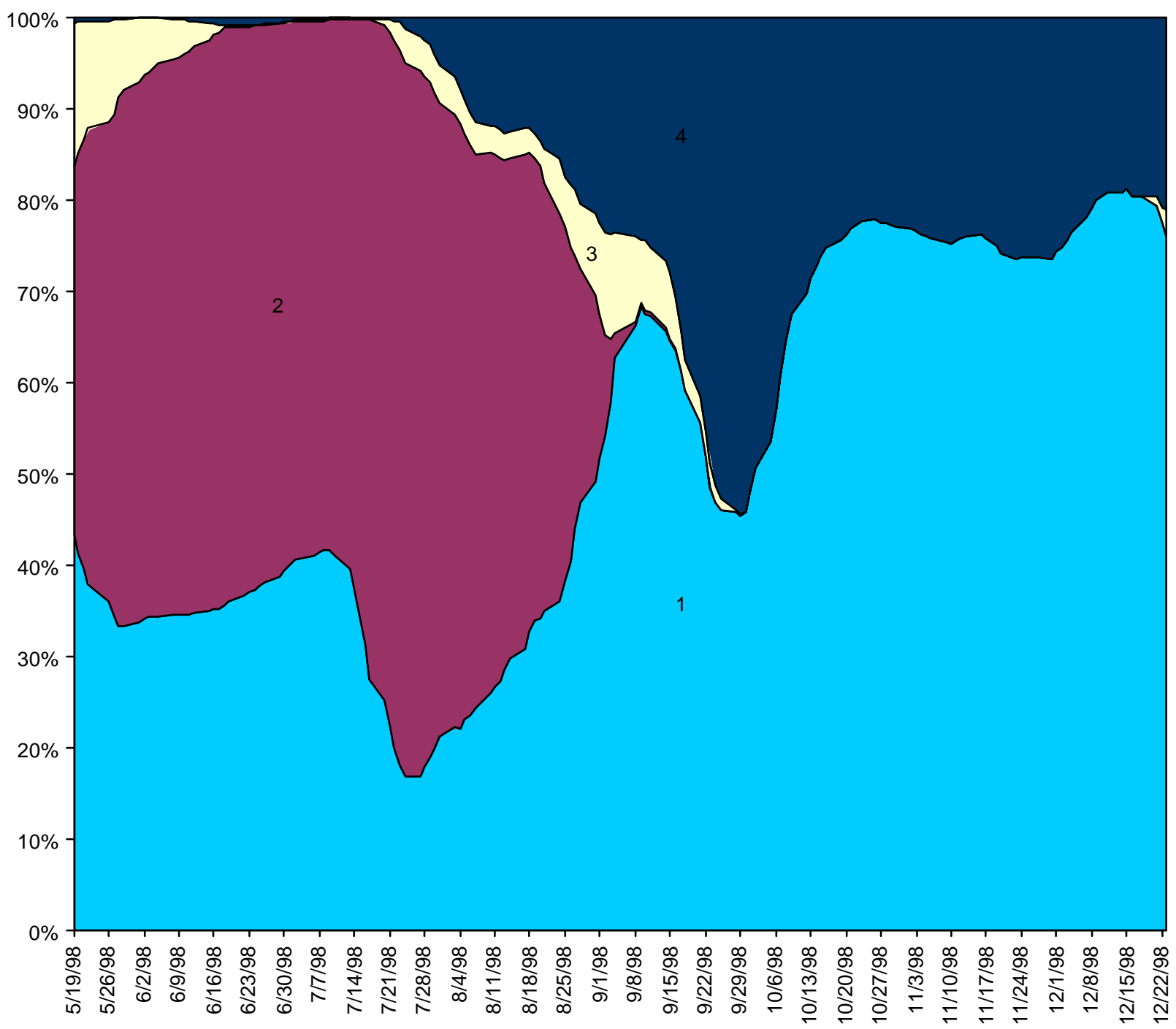

$\square 1$ Return Contrarian Net Purchases $\quad \square 2$ Return Momentum Net Purchases

$\square 3$ Volatility Contrarian Net Purchases $\square 4$ Volatility Momentum Net Purchases 


\section{Figure 2}

Percentage impact of different strategies on market return: breakdown by components

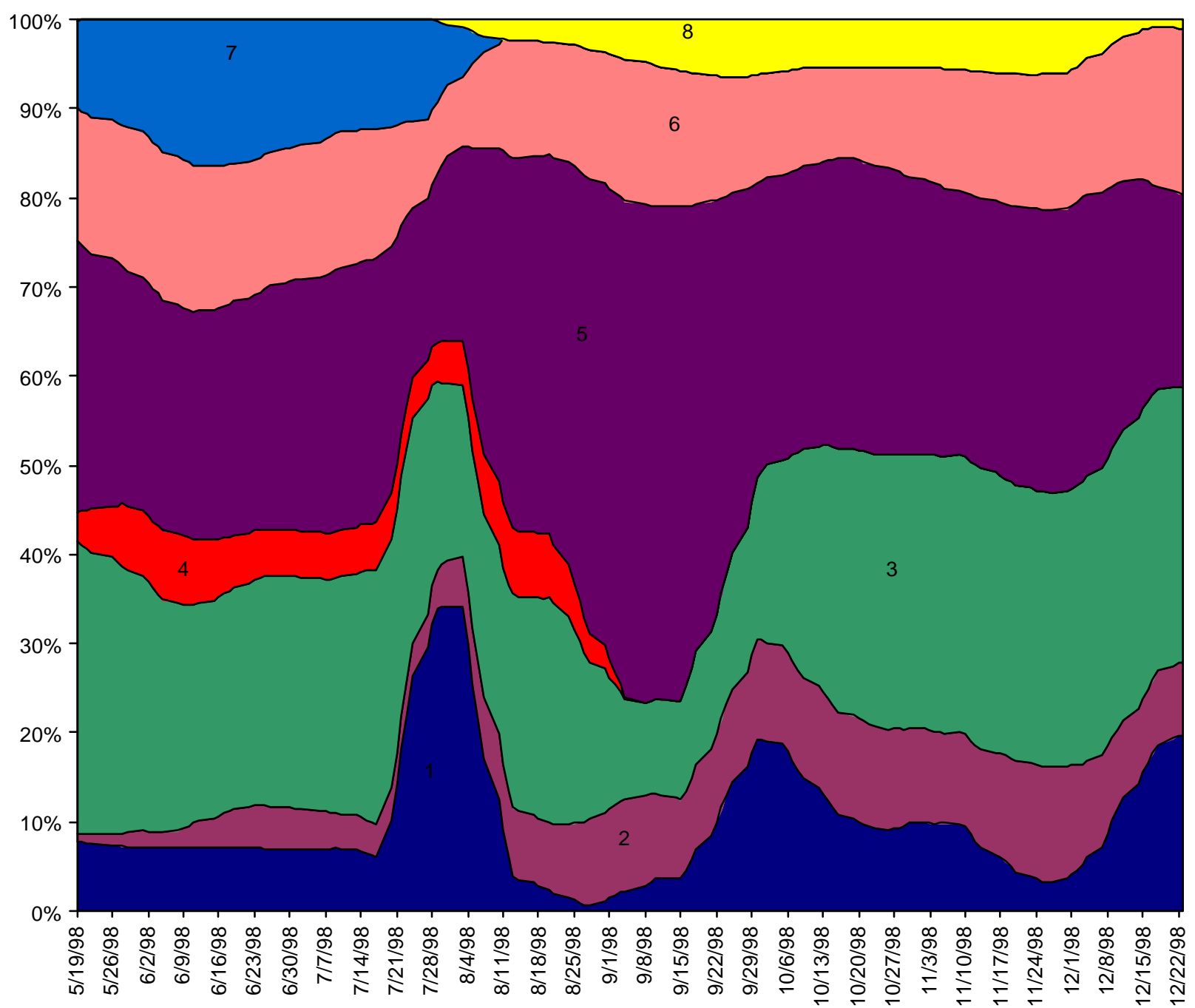

\begin{tabular}{|lll|}
\hline$\square$ 1 Return Contrarian Purchases & $\square 2$ Return Momentum Purchases & $\square 3$ Return Contrarian Sales \\
$\square 4$ Return Momentum Sales & $\square 5$ Volatility Contrarian Purchases & $\square 6$ Volatility Momentum Purchases \\
$\square 7$ Volatility Contrarian Sales & $\square 8$ Volatility Momentum Sales & \\
\hline
\end{tabular}

